\title{
Article \\ Rotating Flow in a Nanofluid with CNT Nanoparticles over a Stretching/Shrinking Surface
}

\author{
Nor Azizah Yacob ${ }^{1}$, Nor Fadhilah Dzulkifli ${ }^{1}$, , Siti Nur Alwani Salleh ${ }^{2} \mathbb{E}$, Anuar Ishak ${ }^{3, *(\mathbb{D})}$ and Ioan Pop ${ }^{4}$ \\ 1 Faculty of Computer and Mathematical Sciences, Universiti Teknologi MARA Pahang, \\ Jengka 26460, Pahang, Malaysia; norazizah872@uitm.edu.my (N.A.Y.);nfd@uitm.edu.my (N.F.D.) \\ 2 Faculty of Computer and Mathematical Sciences, Universiti Teknologi MARA Kedah, \\ Merbok 08400, Kedah, Malaysia; sitinuralwani@uitm.edu.my \\ 3 Department of Mathematical Sciences, Faculty of Science and Technology, Universiti Kebangsaan Malaysia, \\ Bangi 43600, Selangor, Malaysia \\ 4 Department of Mathematics, Babeş-Bolyai University, 400578 Cluj-Napoca, Romania; popm.ioan@yahoo.co.uk \\ * Correspondence: anuar_mi@ukm.edu.my; Tel.: +60-389215785
}

Citation: Yacob, N.A.; Dzulkifli, N.F.; Salleh, S.N.A.; Ishak, A.; Pop, I. Rotating Flow in a Nanofluid with CNT Nanoparticles over a Stretching/Shrinking Surface. Mathematics 2022, 10, 7. https:// doi.org/10.3390/math10010007

Academic Editors: Camelia Petrescu and Valeriu David

Received: 17 November 2021 Accepted: 15 December 2021 Published: 21 December 2021

Publisher's Note: MDPI stays neutral with regard to jurisdictional claims in published maps and institutional affiliations.

Copyright: (C) 2021 by the authors. Licensee MDPI, Basel, Switzerland. This article is an open access article distributed under the terms and conditions of the Creative Commons Attribution (CC BY) license (https:// creativecommons.org/licenses/by/ $4.0 /)$.

\begin{abstract}
The steady three-dimensional rotating flow past a stretching/shrinking surface in water and kerosene-based nanofluids containing single and multi-walled carbon nanotubes (CNTs) is investigated. The governing equations are converted to similarity equations, and then numerically solved using MATLAB software. The impacts of rotational, suction, and nanoparticle volume fraction on the flow and the thermal fields, as well as velocity and temperature gradients at the surface, are represented graphically and are analyzed. Further, the friction factor and the heat transfer rate for different parameters are presented in tables. It is found that the heat transfer rate increases with increasing nanoparticle volume fraction as well as suction parameter in water and kerosenebased nanofluids of single and multi-walled CNTs. However, the increment in the rotating flow parameter decreases the rate of heat transfer. Multi-walled carbon nanotubes and kerosene-based nanofluid contribute to heat transfer rates better than single-walled carbon nanotubes and waterbased nanofluid, respectively. A unique solution exists for the stretching surface, while two solutions are obtained for the shrinking surface. Further analysis of their stabilities shows that only one of them is stable over time.
\end{abstract}

Keywords: carbon nanotubes; heat transfer; nanofluid; rotating; stretching/shrinking

\section{Introduction}

Researchers have begun looking for fluids with high thermal conductivity in the last few decades since traditional fluids have low thermal conductivity. In 1873, Maxwell studied the dispersion of solid particles with a size of millimeters and micrometers in traditional fluids. However, the existence of these particles caused a drastic drop in pressure, clogged flow channels, caused sedimentation of the particles to occur faster and erosion on the channel, and certain particles are too large for the microsystem [1]. Choi and Eastman [1] proposed a new fluid called nanofluid, in which solid particles with sizes ranging from 1-100 $\mathrm{nm}$ are dispersed in traditional fluids such as water, oil, and ethylene glycol. This fluid is significant because of its unique chemical and physical properties, as well as its high thermal conductivity, which can improve the heat transfer rate [2]. Waqas et al. [3] investigated the impact of nanoparticle shape's factor in porous media and discovered that platelet and cylindrical shapes had the highest thermal conductivity compared to brick and spherical shapes. A comprehensive collection of nanofluids studies can be found in [4-9].

Recently, many studies have considered carbon nanotubes as nanoparticles since their thermal conductivity is better and higher than those of traditional fluids. Carbon nanotubes (CNTs) are a sheet of graphene rolled into a cylinder introduced by ligima in 1991. Carbon nanotubes are classified as single-walled (SWCNT) and multi-walled (MWCNT). They have 
a nanometer diameter size which is much smaller than other advanced semiconductor devices, and the length of nanotubes can exceed 1 micrometer. In addition, carbon nanotubes also offer unique electrical characteristics that other semiconductors lack. Further studies on unique features and review of carbon nanotubes can be found through investigation by Popov [10], Patel et al. [11], and Taherian et al. [12].

Due to their performance in optimizing thermal conductivity, researchers carried out many works to study the influence of carbon nanotubes availability and other effects in the fluids on the flow behavior. Khan et al. [13] investigated the fluid flow and heat transmission of CNTs nanofluid over a flat plate using three types of base fluids: water, engine oil, and kerosene. In comparison to water and kerosene-CNTs, they discovered that engine oil-CNTs have the highest heat transfer rate. Using a homogeneous model, Akbar et al. [14] investigated the stagnation-point flow of carbon nanotubes towards a stretching sheet with a magnetic field, velocity slip effect, and convective boundary condition. It was discovered that a higher magnetic field reduces the heat transfer rate at the surface and that single-walled carbon nanotubes have a higher heat transfer rate than multi-walled carbon nanotubes. Later, using similar CNTs nanofluid, Hayat et al. [15] explored the stagnationpoint flow over a nonlinear stretching surface with homogeneous-heterogeneous reactions. Hussain et al. [16] studied a three-dimensional flow of carbon nanotubes nanofluids over a nonlinearly stretching sheet with heat generation/absorption effect in a porous medium. Sreedevi et al. [17] investigated the heat and mass transfer characteristics of nanofluids containing CNTs towards a vertical cone in a porous medium by considering the magnetic field, chemical reaction, and suction/injection parameters. The findings revealed that increasing the nanoparticle volume fraction improves the heat transfer rate, while employing multi-walled CNT. as nanoparticles enhance the heat transfer over single-walled CNT. The latter conclusion was similar to Anuar et al. [18], who analyzed the mixed convection flow towards a moving plate. However, Anuar et al. [18] obtained a different result when the nanoparticle volume fraction increased. Reddy and Sreedevi [19] studied the effects of thermal radiation and single-walled carbon nanotubes inside a square chamber. From their observation, increasing these two factors enhances the heat transfer rate. Ramzan et al. [20] applied the Cattaneo-Christov heat flux model to analyze the impact of nonlinear thermal radiation and thermal stratification on the unsteady magnetohydrodynamics (MHD) flow between two stretching rotatory discs in nanofluid with carbon nanotubes. They discovered that nonlinear thermal radiation gives rise to the temperature of both SWCNT and MWCNT. Relevant studies on CNT nanofluids can be found in [21-23].

Investigation of the rotating flow towards a stretching surface is vital due to its application in a variety of scientific, technical, and product applications, designing and modeling jet engines, pumps, and vacuum cleaners, as well as geophysical flows [24]. Numerical studies on rotating flow have been explored by many researchers such as Singh and Sathi [25], who obtained an exact solution using Laplace transform for an unsteady rotating flow over an infinite plate. Wang [26] was the first to study the rotating flow over a stretching sheet using a perturbation method to identify the velocity profiles of small parameter values. Later, Nazar et al. [27] extended the work of Wang [26] by considering an unsteady flow. This study was expanded by Ali et al. [28] to the shrinking surface, and they obtained dual solutions. Further, Sreelakshmi et al. [29] included the magnetic field and thermal radiation effects in their study. They reported that the magnetic field, thermal radiation parameter, and rotation parameter increase the heat transfer rate. Rosali et al. [30] investigated the rotating flow over an exponentially permeable shrinking surface and found dual solutions. Rana et al. [31] implemented the Boungiorno model to investigate the MHD flow across a stretching surface in a nanofluid and numerically solved using a finite element method. It was revealed that the local Nusselt number and the local Sherwood number drop with the growth of the rotational parameter. By combining the Boungiorno and Tiwari-Das models, Bakar et al. [32] solved a rotating flow towards a shrinking surface with three nanoparticles types: copper, alumina, and titania with water as the base fluid using a shooting method. Different from Rana et al. [31], they found dual solutions, and the 
local Nusselt number and the local Sherwood number increase with rotational parameter. Further, Krishna [33] explored the MHD effect in a Jeffrey fluid on a porous surface with hall and ion slip.

Nadeem et al. [34] explored a rotating flow towards a stretching surface utilizing copper and titania as the nanoparticles with water as the base fluid by applying the TiwariDas model. They discovered that increasing the volume fraction of nanoparticles boosted the heat transfer rate while decreasing it with the rotation parameter. Hayat et al. [15] reported the analytical results of rotating flow with carbon nanotubes over a stretching porosity surface. Dzulkifli et al. [35] continued the study of Ali et al. [28] by considering the unsteady rotation flow on a stretched surface in a nanofluid with copper as nanoparticles. According to the findings, as the rotating parameter and nanoparticle volume percentage grew, the heat transfer rate dropped. Later, Salleh et al. [36] expanded the study by Nadeem et al. [34] to a permeable shrinking surface and obtained dual solutions. A stability analysis was carried out to inspect the stability of the solutions in the long run. As stated by Merkin [37] and Harris et al. [38], the upper branch is always stable, and this discovery is similar to the works made by Salleh et al. [36], Mustafa et al. [39], and Tshivhi and Makinde [40]. Hafeez et al. [41] explored the MHD rotating flow in a hybrid nanofluid using a finite element method. Mehdipour et al. [42] designed a rotating liquid sheet (RLS) contactor to explore carbon dioxide absorption from a gas stream using water-based $\mathrm{SiO}_{2}$ and $\mathrm{ZnO}$ nanofluids. $\mathrm{CO}_{2}$ absorption is more significant in the presence of $\mathrm{ZnO}$ than in the presence of $\mathrm{SiO}_{2}$, and tube rotation can improve absorption performance.

Acharya et al. [43] conducted a comparative investigation of SWCNTs and MWCNTs in a rotating regime over a stretching sheet in the presence of a magnetic field using the RK-4 method. They noticed that increasing the volume fraction of SWCNTs and MWCNTs improved the nanofluid temperature. Later, Shah et al. [44] analyzed a similar investigation over a stretching sheet using an analytical method. Noranuar et al. [45] studied a noncoaxial rotation flow towards a permeable moving disk in an MHD Casson nanofluid. Hussain et al. [46] extended the work of Nadeem et al. [34] by considering engine oil as the base fluid with copper and aluminum dioxide as nanoparticles over a stretching surface with slip condition. They found that copper nanoparticles react as heat carriers better than aluminum oxide. Manjunatha et al. [47] recently performed a numerical analysis to study the effect of a magnetic field on the fluid flow over a rotating disc in a nanofluid using single and multi-walled carbon nanotubes as nanoparticles and water as the base fluid. They reported that a unique solution exists, and the increase in the magnetic field caused an increase in the radial velocity and temperature.

Based on the previous studies mentioned above, many researchers focused on a rotational flow/disk over a stretching surface rather than a permeable stretching/shrinking surface and only obtained a unique solution. A permeable stretching/shrinking surface is vital in industrial applications since the surface may not be static such as polymer extrusion process, liquid crystal, and ceramic production [48]. Therefore, the present study aims to extend the work of Nadeem et al. [34] and Salleh et al. [36] by exploring the impact of rotation flow parameter, suction and nanoparticle volume fraction on the heat and mass transfer characteristics of carbon nanotubes (SWCNTs and MWCNTs) over a permeable stretching/shrinking surface in a nanofluid. Since no studies have considered this mathematical model with carbon nanotubes nanoparticles, the results obtained are genuine and can contribute to the development of this field. The numerical results are obtained using the bvp4c solver in MATLAB software, and a stability analysis is performed to investigate the stability of the solutions as time evolves.

\section{Mathematical Model Description}

A steady 3D rotating boundary layer flow of a carbon nanotube past a stretching or shrinking surface is examined, and its physical model is illustrated in Figure 1. In Figure 1, $x, y$, and $z$ are the Cartesian coordinates with $x$ - and $y$-axes measured in the plane $z=0$ where nanofluid is in the region $z \geq 0$. The boundary $z=0$ is elastic and linearly stretched 
or shrunk by two equal and opposite forces in the direction of the $x$-axis with the velocity $U_{w}=a x$. The fluid is rotating at an angular velocity $\Omega$ in the $z$-direction. It is assumed that the nanofluid has a uniform wall and ambient temperatures, $T_{w}$ and $T_{\infty}$, respectively. Based on the above assumptions, the governing equations of mass, momentum, and energy are (see Nadeem et al. [34] and Salleh et al. [36]):

$$
\begin{gathered}
\frac{\partial u}{\partial x}+\frac{\partial v}{\partial y}+\frac{\partial w}{\partial z}=0 \\
u \frac{\partial u}{\partial x}+v \frac{\partial u}{\partial y}+w \frac{\partial u}{\partial z}-2 \Omega v=\frac{\mu_{n f}}{\rho_{n f}} \frac{\partial^{2} u}{\partial z^{2}} \\
u \frac{\partial v}{\partial x}+v \frac{\partial v}{\partial y}+w \frac{\partial v}{\partial z}+2 \Omega u=\frac{\mu_{n f}}{\rho_{n f}} \frac{\partial^{2} v}{\partial z^{2}}
\end{gathered}
$$

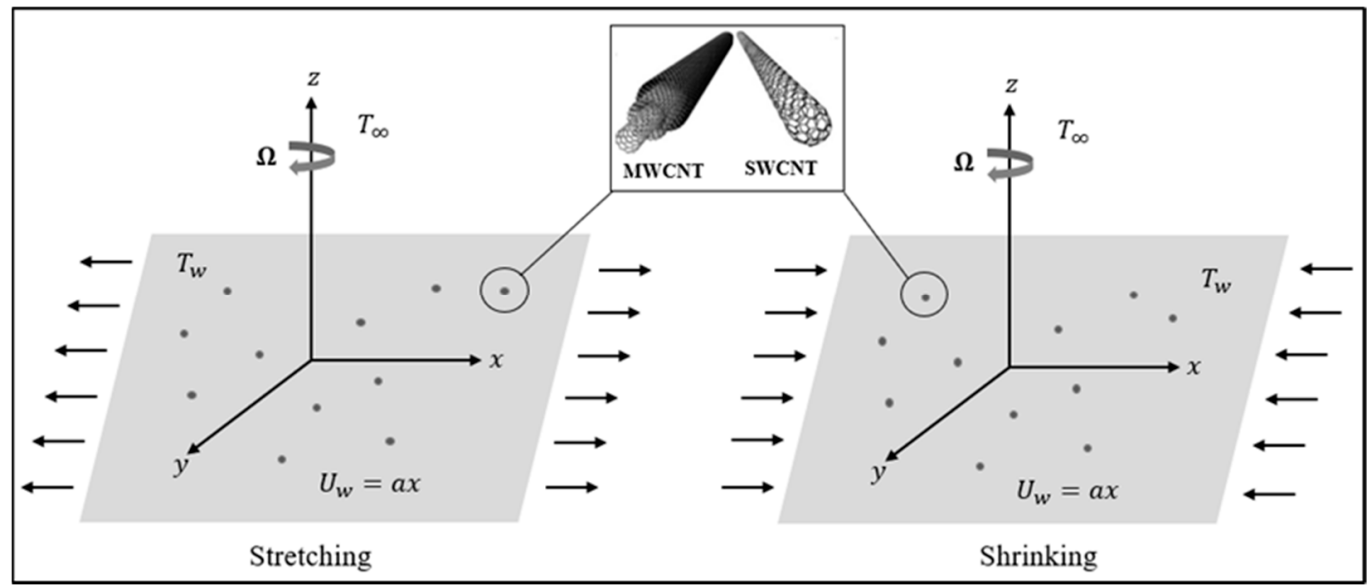

Figure 1. Physical model of the problem.

$$
u \frac{\partial T}{\partial x}+v \frac{\partial T}{\partial y}+w \frac{\partial T}{\partial z}=\alpha_{n f} \frac{\partial^{2} T}{\partial z^{2}}
$$

The boundary conditions are

$$
\begin{gathered}
u=\varepsilon U_{w}, v=0, w=-w_{0}, T=T_{w} \text { at } z=0, \\
u \rightarrow 0, v \rightarrow 0, T \rightarrow T_{\infty} \text { as } z \rightarrow \infty
\end{gathered}
$$

where $u, v$, and $w$ represent the velocity components in the $x_{-}^{-}, y_{-}$, and $z$-directions, respectively, $T$ represents the fluid temperature, $w_{0}$ is the constant mass flux with $w_{0}>0$ indicates injection, while $w_{0}<0$ is for suction. Further, $\varepsilon$ is the stretching or shrinking parameter with $\varepsilon>0$ for stretching, $\varepsilon<0$ for shrinking and $\varepsilon=0$ for the static surface. In this study, we adopt the theoretical model proposed by Xue [49] as follows:

$$
\begin{gathered}
\mu_{n f}=\frac{\mu_{f}}{(1-\varphi)^{2.5}}, \alpha_{n f}=\frac{k_{n f}}{\left(\rho C_{p}\right)_{n f}}, \frac{k_{n f}}{k_{f}}=\frac{1-\varphi+2 \varphi \frac{k_{c n t}}{k_{c n t}-k_{f}} \ln \frac{k_{c n t}+k_{f}}{2 k_{f}}}{1-\varphi+2 \varphi \frac{k_{f}}{k_{c n t}-k_{f}} \ln \frac{k_{c n t}+k_{f}}{2 k_{f}}}, \\
\rho_{n f}=(1-\varphi) \rho_{f}+\varphi \rho_{c n t},\left(\rho C_{p}\right)_{n f}=(1-\varphi)\left(\rho C_{p}\right)_{f}+\varphi\left(\rho C_{p}\right)_{c n t} .
\end{gathered}
$$

In Equation (6), $\mu$ is dynamic viscosity, $\rho$ is density, $\alpha$ is thermal diffusivity, $k$ is thermal conductivity, $C_{p}$ is the specific heat capacity at constant pressure, $\varphi$ is nanoparticle volume fraction parameter in which the subscripts $n f, f$, and $c n t$, respectively, refer to nanofluid, fluid, and carbon nanotube. 
The thermophysical properties of SWCNT and MWCNT for different base fluids namely, water $(\mathrm{Pr}=6.2)$ and kerosene $(\mathrm{Pr}=21)$ at the temperature $20-25{ }^{\circ} \mathrm{C}$ are given in Table 1 (Khan et al. [13]). Water and kerosene are chosen as the base fluids for comparison with the previous studies. Furthermore, water has the highest specific heat that can stabilize the temperature and is used as a cooling agent, while oil-based nanofluids are often utilized in industrial operations for lubrication or high-temperature applications [50]. The following similarity transformations (7) are introduced for solving Equations (2)-(4) together with the boundary conditions (5) that satisfy the continuity Equation (1).

$$
u=a x f^{\prime}(\eta), v=\operatorname{axh}(\eta), w=-\sqrt{a v_{f}} f(\eta), \eta=\sqrt{\frac{a}{v_{f}}} z, \theta(\eta)=\frac{T-T_{\infty}}{T_{w}-T_{\infty}}
$$

Table 1. Thermophysical properties of base fluids and carbon nanotubes.

\begin{tabular}{ccccc}
\hline \multirow{2}{*}{ Physical Properties } & \multicolumn{2}{c}{ Base Fluids } & \multicolumn{2}{c}{ Nanoparticles } \\
\cline { 2 - 5 } & Water $(\mathbf{P r}=6.2)$ & Kerosene $\mathbf{( P r}=21)$ & SWCNT & MWCNT \\
\hline$\rho\left(\mathrm{kg} / \mathrm{m}^{3}\right)$ & 997 & 783 & 2600 & 1600 \\
$C_{p}(\mathrm{~J} / \mathrm{kgK})$ & 4179 & 2090 & 425 & 796 \\
$k(\mathrm{~W} / \mathrm{mK})$ & 0.613 & 0.145 & 6600 & 3000 \\
\hline
\end{tabular}

From Equation (7), the velocity mass flux can be defined as

$$
w_{0}=-\sqrt{a v_{f}} S
$$

where $S=f(0), S$ is the suction parameter in which $S<0$ for injection and $S>0$ for suction. Substituting Equations (6) and (7) into Equations (2)-(5) yields

$$
\begin{aligned}
& \frac{1}{(1-\varphi)^{2.5}\left[1-\varphi+\varphi\left(\rho_{c n t} / \rho_{f}\right)\right]} f^{\prime \prime \prime}+f f^{\prime \prime}-f^{\prime 2}+2 \omega h=0 \\
& \frac{1}{(1-\varphi)^{2.5}\left[1-\varphi+\varphi\left(\rho_{c n t} / \rho_{f}\right)\right]} h^{\prime \prime}+f h^{\prime}-f^{\prime} h-2 \omega f^{\prime}=0 \\
& \frac{k_{n f} / k_{f}}{\operatorname{Pr}\left[1-\varphi+\varphi\left(\rho C_{p}\right)_{c n t} /\left(\rho C_{p}\right)_{f}\right]} \theta^{\prime \prime}+f \theta^{\prime}=0
\end{aligned}
$$

The BCs (5) become

$$
\begin{gathered}
(0)=S, h(0)=0, f^{\prime}(0)=\varepsilon, \theta(0)=1, \\
h(\eta) \rightarrow 0, f^{\prime}(\eta) \rightarrow 0, \theta(\eta) \rightarrow 0 \text { as } \eta \rightarrow \infty .
\end{gathered}
$$

In Equations (9)-(12), prime denotes the differentiation w.r.t. similarity variable $\eta$, $\omega=\Omega / a$ is the rotation parameter, and Pr is the Prandtl number.

The quantities of physical interest are the skin friction coefficients and the local Nusselt number (heat transfer rate at the surface). The skin friction coefficients in the $x$ - and $y$ directions, respectively, are given by:

$$
C_{f x}=\frac{\tau_{x z}}{\rho_{f} U_{w}^{2}}, C_{f y}=\frac{\tau_{y z}}{\rho_{f} U_{w}^{2}}
$$

The local Nusselt number $N u_{x}$ is defined as:

$$
N u_{x}=\frac{x q_{w}}{k_{f}\left(T_{w}-T_{\infty}\right)}
$$


The shear stresses $\tau_{x z}, \tau_{y z}$ and the heat flux $q_{w}$ at the surface are given by:

$$
\tau_{x z}=\mu_{n f}\left(\frac{\partial u}{\partial z}\right)_{z=0}, \tau_{y z}=\mu_{n f}\left(\frac{\partial v}{\partial z}\right)_{z=0}, q_{w}=-k_{n f}\left(\frac{\partial T}{\partial z}\right)_{z=0}
$$

Using Equation (15), Equations (13) and (14) become

$$
\begin{aligned}
\operatorname{Re}_{x}^{\frac{1}{2}} C_{f x}= & \frac{1}{(1-\varphi)^{2.5}} f^{\prime \prime}(0), \operatorname{Re}_{x}^{\frac{1}{2}} C_{f y}=\frac{1}{(1-\varphi)^{2.5}} h^{\prime}(0), \\
& \operatorname{Re}_{x}^{-1 / 2} N u_{x}=-\frac{k_{n f}}{k_{f}} \theta^{\prime}(0) .
\end{aligned}
$$

where $R e_{x}=U x / v_{f}$ is the local Reynold number.

\section{Stability Analysis}

To investigate the stability of the solutions of Equations (9)-(12) over time, the unsteady case of Equations (2)-(4) are considered as [37,51]

$$
\begin{gathered}
\frac{\partial u}{\partial t}+u \frac{\partial u}{\partial x}+v \frac{\partial u}{\partial y}+w \frac{\partial u}{\partial z}-2 \Omega v=\frac{\mu_{n f}}{\rho_{n f}} \frac{\partial^{2} u}{\partial z^{2}} \\
\frac{\partial v}{\partial t}+u \frac{\partial v}{\partial x}+v \frac{\partial v}{\partial y}+w \frac{\partial v}{\partial z}+2 \Omega u=\frac{\mu_{n f}}{\rho_{n f}} \frac{\partial^{2} v}{\partial z^{2}} \\
\frac{\partial T}{\partial t}+u \frac{\partial T}{\partial x}+v \frac{\partial T}{\partial y}+w \frac{\partial T}{\partial z}=\alpha_{n f} \frac{\partial^{2} T}{\partial z^{2}}
\end{gathered}
$$

where $t$ refers to time. Next, new dimensionless variables are introduced as follows:

$$
\begin{gathered}
\tau=\frac{U t}{x}, u=a x \frac{\partial f}{\partial \eta}(\eta, \tau), v=\operatorname{axh}(\eta, \tau), w=-\sqrt{a v_{f}} f(\eta, \tau), \eta=\sqrt{\frac{a}{v_{f}}} z, \\
\theta(\eta, \tau)=\frac{T-T_{\infty}}{T_{w}-T_{\infty}}
\end{gathered}
$$

By utilizing Equation (20), Equations (17)-(19) become:

$$
\begin{gathered}
\frac{1}{(1-\varphi)^{2.5}\left[1-\varphi+\varphi\left(\rho_{c n t} / \rho_{f}\right)\right]} \frac{\partial^{3} f}{\partial \eta^{3}}+f \frac{\partial^{2} f}{\partial \eta^{2}}-\left(\frac{\partial f}{\partial \eta}\right)^{2}+2 \omega h-\frac{\partial^{2} f}{\partial \eta \partial \tau}=0 . \\
\frac{1}{(1-\varphi)^{2.5}\left[1-\varphi+\varphi\left(\rho_{c n t} / \rho_{f}\right)\right]} \frac{\partial^{2} h}{\partial \eta^{2}}+f \frac{\partial h}{\partial \eta}-h \frac{\partial f}{\partial \eta}-2 \omega \frac{\partial f}{\partial \eta}-\frac{\partial h}{\partial \tau}=0 . \\
\frac{k_{n f} / k_{f}}{\operatorname{Pr}\left[1-\varphi+\varphi\left(\rho C_{p}\right)_{c n t} /\left(\rho C_{p}\right)_{f}\right]} \frac{\partial^{2} \theta}{\partial \eta^{2}}+f \frac{\partial \theta}{\partial \eta}-\frac{\partial \theta}{\partial \tau}=0
\end{gathered}
$$

where their respective boundary conditions are

$$
\begin{aligned}
& f(0, \tau)=S, h(0, \tau)=0, \frac{\partial f}{\partial \eta}(0, \tau)=\varepsilon, \theta(0, \tau)=1, \\
& h(\eta, \tau) \rightarrow 0, \frac{\partial f}{\partial \eta}(\eta, \tau) \rightarrow 0, \theta(\eta, \tau) \rightarrow 0 \text { as } \eta \rightarrow \infty .
\end{aligned}
$$

The stability of the steady flow solutions $f(\eta)=f_{0}(\eta), h(\eta)=h_{0}(\eta)$, and $\theta(\eta)=\theta_{0}(\eta)$ can be determined by writing $f(\eta, \tau), h(\eta, \tau)$ and $\theta(\eta, \tau)$ as follows [51]:

$$
\begin{gathered}
f(\eta, \tau)=f_{0}(\eta)+e^{-\gamma \tau} F(\eta, \tau), h(\eta, \tau)=h_{0}(\eta)+e^{-\gamma \tau} H(\eta, \tau), \\
\theta(\eta, \tau)=\theta_{0}(\eta)+e^{-\gamma \tau} G(\eta, \tau) .
\end{gathered}
$$


In Equation (25), $F(\eta, \tau), H(\eta, \tau)$, and $G(\eta, \tau)$ are smaller relative to $f=f_{0}(\eta)$, $h=h_{0}(\eta)$ and $\theta=\theta_{0}(\eta)$, respectively, and $\gamma$ is the eigenvalue. Substituting Equation (25) into Equations (21)-(24), the following system of linear eigenvalue problem is obtained:

$$
\begin{gathered}
\frac{1}{(1-\varphi)^{2.5}\left[1-\varphi+\varphi\left(\rho_{c n t} / \rho_{f}\right)\right]} \frac{\partial^{3} F}{\partial \eta^{3}}+f_{0} \frac{\partial^{2} F}{\partial \eta^{2}}+F \frac{\partial^{2} f_{0}}{\partial \eta^{2}}-2 \frac{\partial f_{0}}{\partial \eta} \frac{\partial F}{\partial \eta}+2 \omega H \\
+\gamma \frac{\partial F}{\partial \eta}-\frac{\partial^{2} F}{\partial \eta \partial \tau}=0 \\
\frac{1}{(1-\varphi)^{2.5}\left[1-\varphi+\varphi\left(\frac{\rho_{c n t}}{\rho_{f}}\right)\right]} \frac{\partial^{2} H}{\partial \eta^{2}}+f_{0} \frac{\partial H}{\partial \eta}+F \frac{\partial h_{0}}{\partial \eta}-H \frac{\partial f_{0}}{\partial \eta}-h_{0} \frac{\partial F}{\partial \eta}+\gamma H \\
-\frac{\partial H}{\partial \tau}-2 \omega \frac{\partial F}{\partial \eta}=0 \\
\frac{k_{n f} / k_{f}}{\operatorname{Pr}\left[1-\varphi+\varphi\left(\rho C_{p}\right)_{c n t} /\left(\rho C_{p}\right)_{f}\right]} \frac{\partial^{2} G}{\partial \eta^{2}}+f_{0} \frac{\partial G}{\partial \eta}+F \frac{\partial \theta_{0}}{\partial \eta}+\gamma G-\frac{\partial G}{\partial \tau}=0
\end{gathered}
$$

subject to the boundary conditions

$$
\begin{aligned}
& F(0, \tau)=0, H(0, \tau)=0, \frac{\partial F}{\partial \eta}(0, \tau)=0, G(0, \tau)=0 \\
& H(\eta, \tau) \rightarrow 0, \frac{\partial F}{\partial \eta}(\eta, \tau) \rightarrow 0, G(\eta, \tau) \rightarrow 0 \text { as } \eta \rightarrow \infty
\end{aligned}
$$

Following Weidman et al. [51], we take $\tau=0$ to determine the initial decay or growth of the solutions in Equation (25) and functions $F, H$, and $G$ can be written as $F_{0}(\eta), H_{0}(\eta)$, and $G_{0}(\eta)$, respectively. Thus, Equations (26)-(29) can be simplified as

$$
\begin{aligned}
& \frac{1}{(1-\varphi)^{2.5}\left[1-\varphi+\varphi\left(\rho_{c n t} / \rho_{f}\right)\right]} F_{0}^{\prime \prime \prime}+f_{0} F_{0}^{\prime \prime}+F_{0} f_{0}^{\prime \prime}-2 f_{0}^{\prime} F_{0}^{\prime}+2 \omega H_{0}+\gamma F_{0}^{\prime}=0 \\
& \frac{1}{(1-\varphi)^{2.5}\left[1-\varphi+\varphi\left(\frac{\rho_{c n t}}{\rho_{f}}\right)\right]} H_{0}^{\prime \prime}+f_{0} H_{0}^{\prime}+F_{0} h_{0}^{\prime}-H_{0} f_{0}^{\prime}-h_{0} F_{0}^{\prime}+\gamma H_{0}-2 \omega F_{0}^{\prime}=0 \\
& \frac{1}{(1-\varphi)^{2.5}\left[1-\varphi+\varphi\left(\frac{\rho_{c n t}}{\rho_{f}}\right)\right]} H_{0}^{\prime \prime}+f_{0} H_{0}^{\prime}+F_{0} h_{0}^{\prime}-H_{0} f_{0}^{\prime}-h_{0} F_{0}^{\prime}+\gamma H_{0}-2 \omega F_{0}^{\prime}=0
\end{aligned}
$$

subjected to the conditions

$$
\begin{gathered}
F_{0}(0)=0, H_{0}(0)=0, F_{0}^{\prime(0)}=0, G_{0}(0)=0, \\
H_{0}(\eta) \rightarrow 0, F_{0}^{\prime}(\eta) \rightarrow 0, G_{0}(\eta) \rightarrow 0 \text { as } \eta \rightarrow \infty
\end{gathered}
$$

According to Harris et al. [38], the value of the smallest eigenvalue $\gamma$ can be computed by relaxing the boundary conditions on $F_{0}(\eta), H_{0}(\eta)$ or $G_{0}(\eta)$. In this study, the condition $F_{0}^{\prime}(\eta) \rightarrow 0$ as $\eta \rightarrow \infty$ is selected to be relaxed, thus, Equations (30)-(33) are solved along with a new boundary condition $F_{0}^{\prime \prime}(0)=1$ using bvp4c solver in MATLAB software.

\section{Results and Discussion}

The system of nonlinear ordinary differential Equations (8)-(10) associated with the boundary conditions (11) was numerically computed for the diverse values of physical emerging parameters, namely, rotation parameter $\omega$, stretching or shrinking parameter $\varepsilon$, nanoparticle volume fraction parameter $\varphi$, and suction parameter $S$. Two types of base fluids, which are water ( $\operatorname{Pr}=6.2)$ and kerosene $(\operatorname{Pr}=21)$, were considered using both SWCNT and MWCNT. Numerical outcomes are obtained through the function bvp4c in MATLAB software are displayed in graphs and tables [52]. The numerical values of the velocity gradients at the surface of $x$-component $f^{\prime \prime}(0)$ and $y$-component $h^{\prime}(0)$ were compared with the previous work of Wang [26] and Mustafa et al. [53] in the absence of 
stretching/shrinking parameter $(\varepsilon=0)$, nanoparticle volume fraction $(\varphi=0)$, and suction parameter $(S=0)$ for SWCNTs using water as the base fluid. Those values are listed in Table 2, and the acquired results were deemed adequate compared to previously obtained data by Wang [26] and Mustafa et al. [53]. Dual solutions are obtained as depicted in Figures 2-14, and it was worth performing a stability analysis as described in Section 2 to identify the stability of the solutions. The finding of stability analysis is discussed at the end of Section 3.

Table 2. Comparison values of $f^{\prime \prime}(0)$ and $h^{\prime}(0)$ for multiple values of rotation parameter $\omega$ when $\varepsilon=\varphi=S=0$ and $\operatorname{Pr}=6.2$ (water) for SWCNT.

\begin{tabular}{ccccccc}
\hline \multirow{2}{*}{$\omega$} & \multicolumn{2}{c}{ Wang [26] } & \multicolumn{2}{c}{ Mustafa et al. [53] } & \multicolumn{2}{c}{ Present Study } \\
\cline { 2 - 6 } & $\boldsymbol{f}^{\prime}(0)$ & $\boldsymbol{h}^{\prime}(0)$ & $\boldsymbol{f}^{\prime}(0)$ & $\boldsymbol{h}^{\prime}(0)$ & $\boldsymbol{f}^{\prime}(0)$ & $\boldsymbol{h}^{\prime}(0)$ \\
\hline 0 & -1 & 0 & -1 & 0 & -1 & 0 \\
0.5 & -1.1384 & -0.5128 & -1.13838 & -0.51276 & -1.138381 & -0.512760 \\
1.0 & -1.3250 & -0.8371 & -1.32503 & -0.83709 & -1.325029 & -0.837098 \\
2.0 & -1.6523 & -1.2873 & -1.65235 & -1.28726 & -1.652352 & -1.287259 \\
\hline
\end{tabular}

In this paper, the results in Figures 2-14 and Tables 3-6 are presented to discuss the impact of various physical parameters on the physical quantities of interest, such as the local skin friction coefficients $R e_{x}^{1 / 2} C_{f x}$ and $R e_{x}^{1 / 2} C_{f y}$, and the local Nusselt number $R e_{x}^{-1 / 2} N u_{x}$, which are proportional to $f^{\prime \prime}(0), h^{\prime}(0)$ and $-\theta^{\prime}(0)$, respectively, as well as the velocity and temperature profiles. Figures 2 and 3 present the variation of $f^{\prime \prime}(0)$ and $h^{\prime}(0)$ for several values of rotation parameter $\omega$ versus stretching or shrinking parameter $\varepsilon$ for SWCNT using water as the base fluid. These figures reveal that rising $\omega$ causes the gradients $f^{\prime \prime}(0)$ and $h^{\prime}(0)$ to grow. However, it is noted that $h^{\prime}(0)$ becomes zero when there is no rotation in the flow or when $\omega=0$. Further, a higher rotation rate causes fluid to move faster, which accelerates the velocity. The drag force between the fluid and the surface expedites and consequently increases the velocity gradient for both components. In addition, an increase in the values of $f^{\prime \prime}(0)$ and $h^{\prime}(0)$ is due to the decrement in the momentum boundary layer thickness as $\omega$ increases (see Figure 7; Figure 8). Besides, as the stretching or shrinking parameter changes from the negative value to the positive one, both values of $f^{\prime \prime}(0)$ and $h^{\prime}(0)$ seems to decrease. It happens because when the surface shrinks, less friction occurs on the surface than on the stretching surface. The rotating fluid forces the friction to appear in the flow significantly when the surface is being compressed. As a result, the velocity gradients rise for the shrinking surface compared to the stretching surface. Furthermore, the emergence of dual solutions is noticed when $\varepsilon$ is in the region of $\varepsilon_{\mathcal{c}}<\varepsilon \leq-0.8$. Meanwhile, unique solutions are obtained when $\varepsilon>-0.8$ and no solutions when $\varepsilon<\varepsilon_{c}$.

The variation of $f^{\prime \prime}(0)$ and $h^{\prime}(0)$ and $-\theta^{\prime}(0)$ for some values of nanoparticle volume fraction parameter $\varphi$ versus suction parameter $S$ are plotted in Figures 4-6 for MWCNT using kerosene as the base fluid. It is found from these plots that increasing the values of $\varphi$ tends to diminish the $f^{\prime \prime}(0)$ and $-\theta^{\prime}(0)$. However, the reverse effect is noted for $h^{\prime}(0)$ since adding more nanoparticles in the flow will slow down the collision between the molecules of the base fluid and nanoparticles, which in turn reduces $f^{\prime \prime}(0)$.

Since the surface is compressed or stretched in the $x$-direction, thus, the effect of $\varphi$ on $f^{\prime \prime}(0)$ is more pronounced than $h^{\prime}(0)$. As noticed in Figure 5 , there is a slight increase in the value of $h^{\prime}(0)$ when $\varphi$ increases. Besides, the reduction in $-\theta^{\prime}(0)$, as displayed in Figure 6, is due to the thickening of the thermal boundary layer thickness as $\varphi$ increases. This phenomenon prevents heat from the surface from being transferred to the surrounding fluid, and consequently, reduces $-\theta^{\prime}(0)$. It is also revealed that as $S$ intensifies, $f^{\prime \prime}(0)$ and $-\theta^{\prime}(0)$ seem to increase, while the contrary phenomenon is noticed for $h^{\prime}(0)$. The increment of $-\theta^{\prime}(0)$ is influenced by the surface texture where suction causes heat to be transferred from the wall to the fluid. It is observed that non-unique solutions occur for the particular 
values of the suction parameter and no solutions when $S<S_{c}$. Figure 4 reveals that in the case of regular fluid $(\varphi=0)$, dual solutions exist in the range of $S_{c}=1.9965<S \leq 2.31$. Meanwhile, as the value of $\varphi$ increases from 0 to 0.02 and 0.04 , dual solutions are obtained in the range of $S_{c}=2.0265<S \leq 2.34$ and $S_{c}=2.0584<S \leq 2.38$, respectively. As can be seen in Figures 2-5, the range of solutions that exist are different based on the pertinent parameters involved. Figures 2 and 3 show that when different values of $\omega$ are plotted versus $\varepsilon$, the range of solutions increases with an increasing rotation parameter $\omega$. However, Figures 4 and 5 depict that it decreases when the nanoparticle volume fraction $\varphi$ increases.

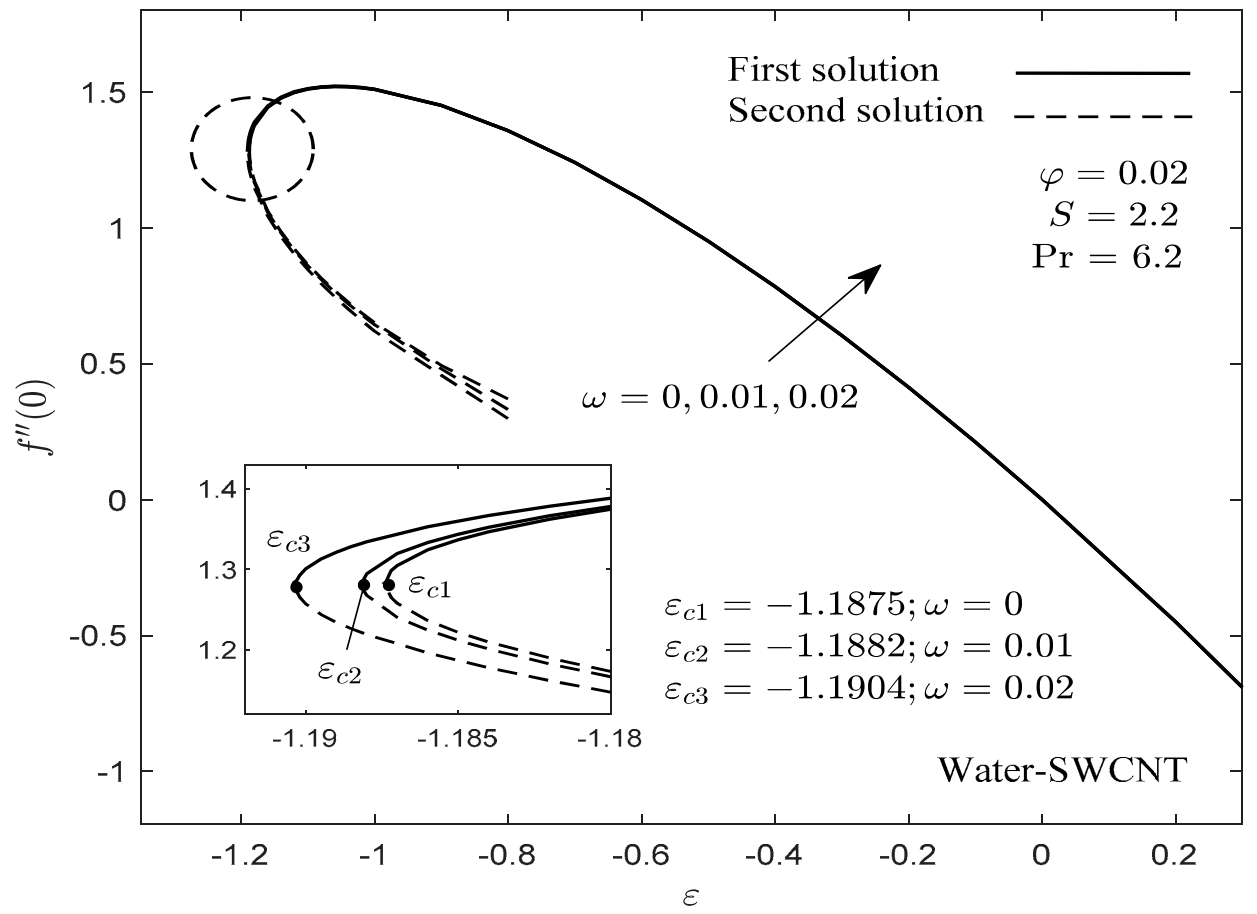

Figure 2. Values of $f^{\prime \prime}(0)$ for some values of $\omega$ versus $\varepsilon$.

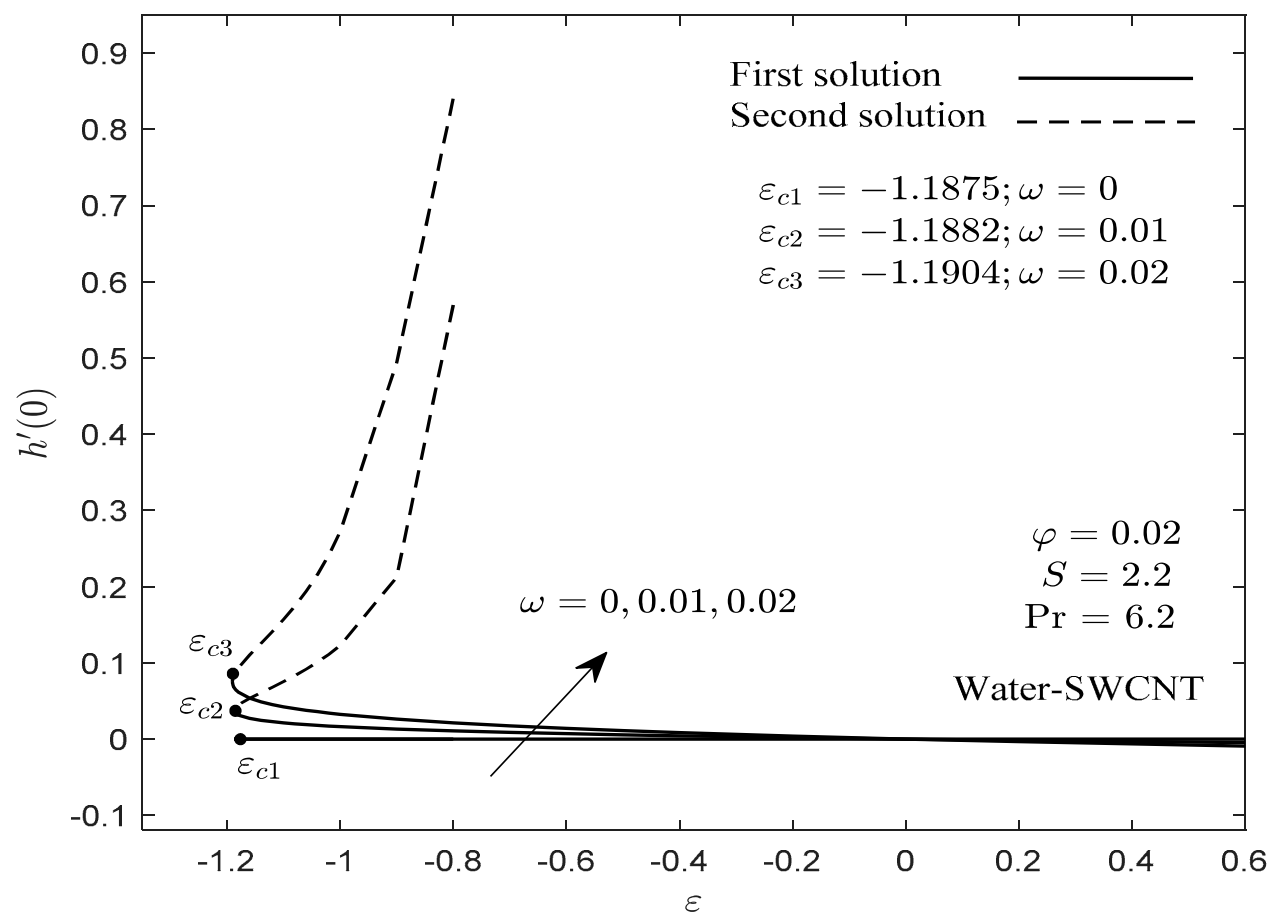

Figure 3. Values of $h^{\prime}(0)$ for some values of $\omega$ versus $\varepsilon$. 


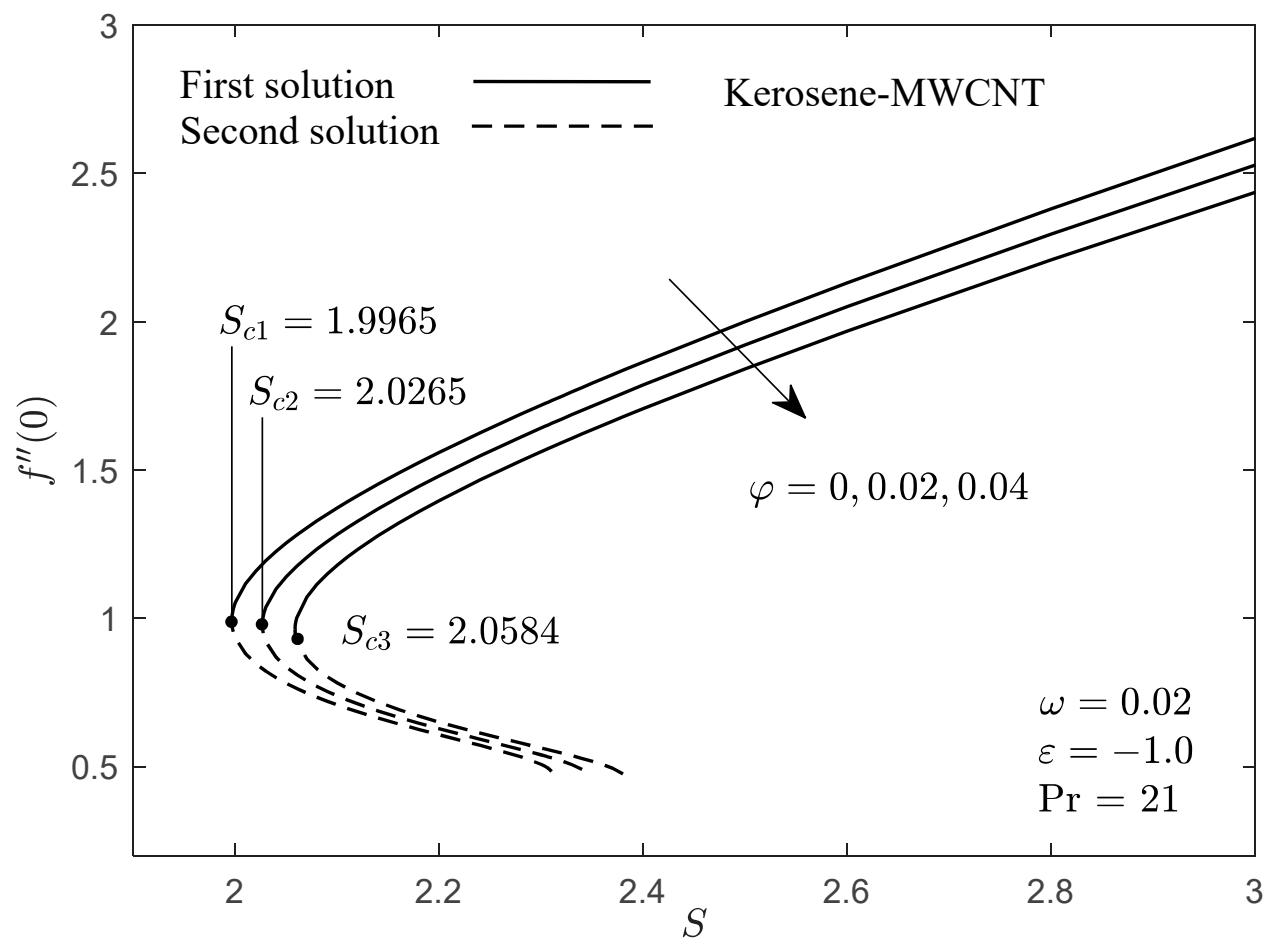

Figure 4. Values of $f^{\prime \prime}(0)$ for some values of $\varphi$ versus $S$.

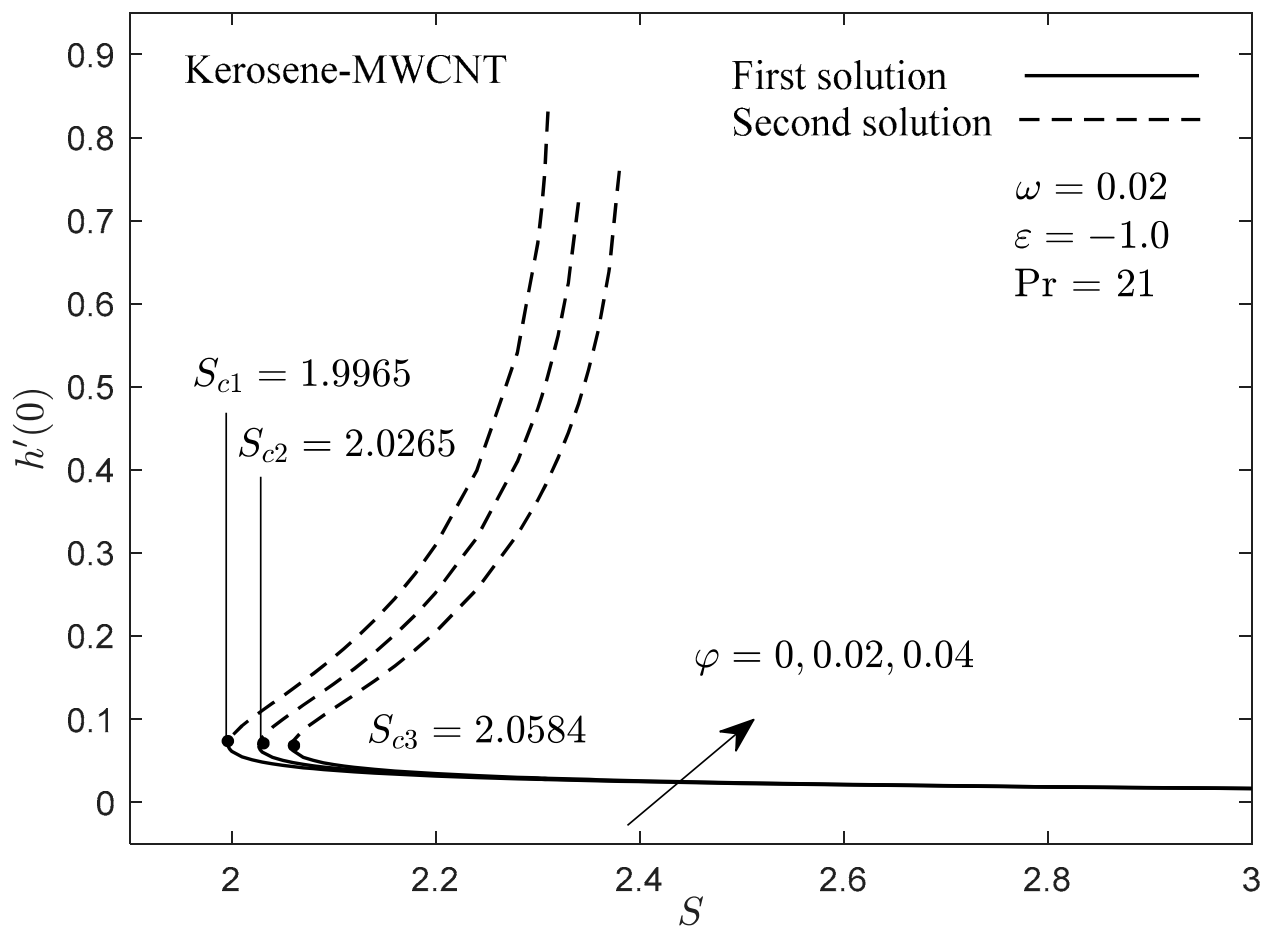

Figure 5. Values of $h^{\prime}(0)$ for some values of $\varphi$ versus $S$.

Figures 7-14 illustrate the velocities of $x$ - and $y$-components, $f^{\prime}(\eta)$ and $h(\eta)$ as well as the temperature profiles $\theta(\eta)$ for multiple values of $\omega, \varphi$ and $S$ for different base fluids. As can be seen in Figures 7 and 8 , both velocities of $x$ - and $y$-components enhance with a higher rotation parameter for the first solution. An increase in the rotation rate will force the fluid to move rapidly and, in the meantime, accelerate both velocity components. This behavior will complicate the formation of the boundary layer thickness; thus, the boundary layer thickness becomes thinner. In contrast, the opposite phenomenon is reported for 
the second solution. Furthermore, it is found that the velocity of $x$-component decreases; meanwhile, the velocity of $y$-component and the temperature fields for the first solution show an increment with the increasing $\varphi$ as displayed in Figures 9-11, respectively.

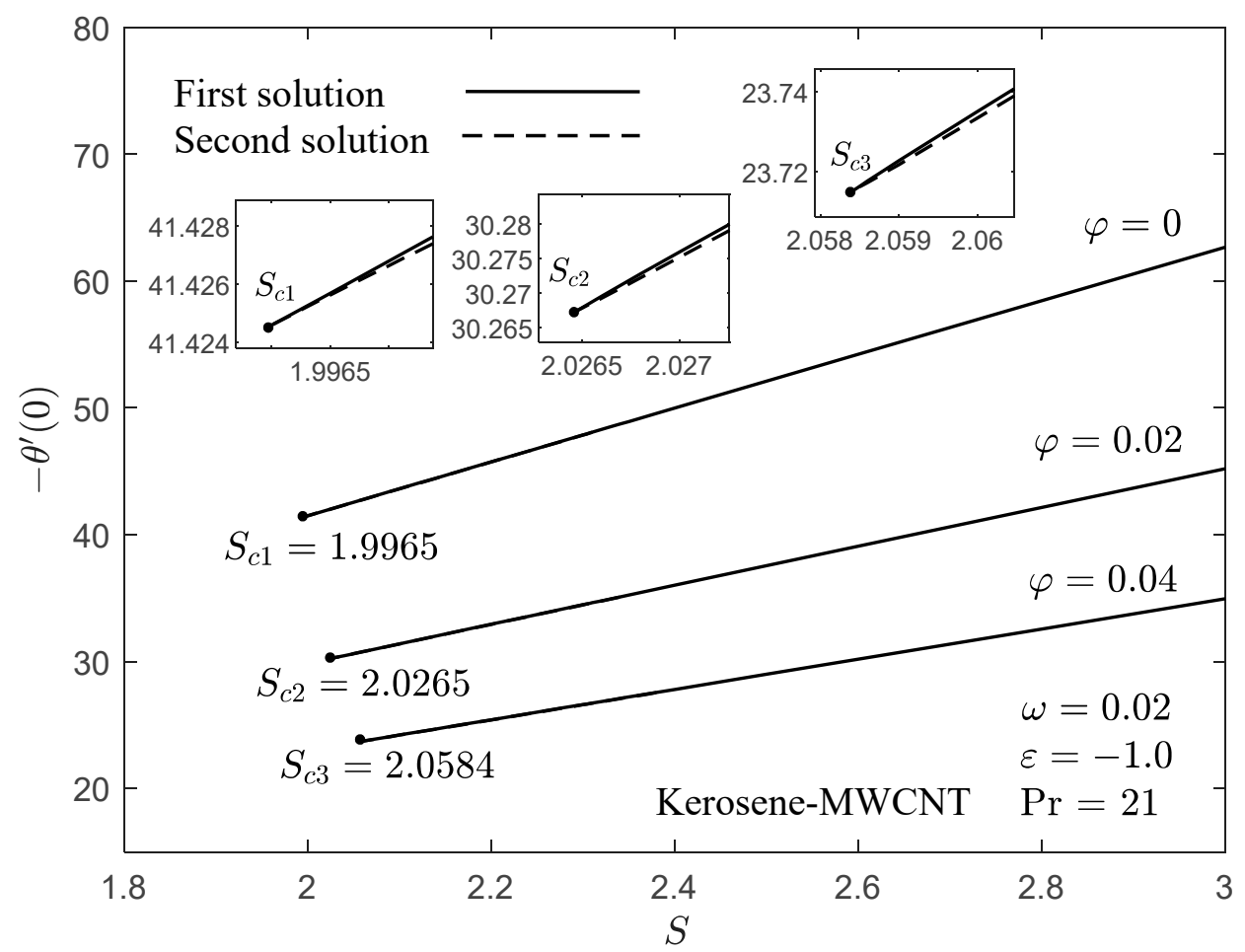

Figure 6. Values of $-\theta^{\prime}(0)$ for some values of $\varphi$ versus $S$.

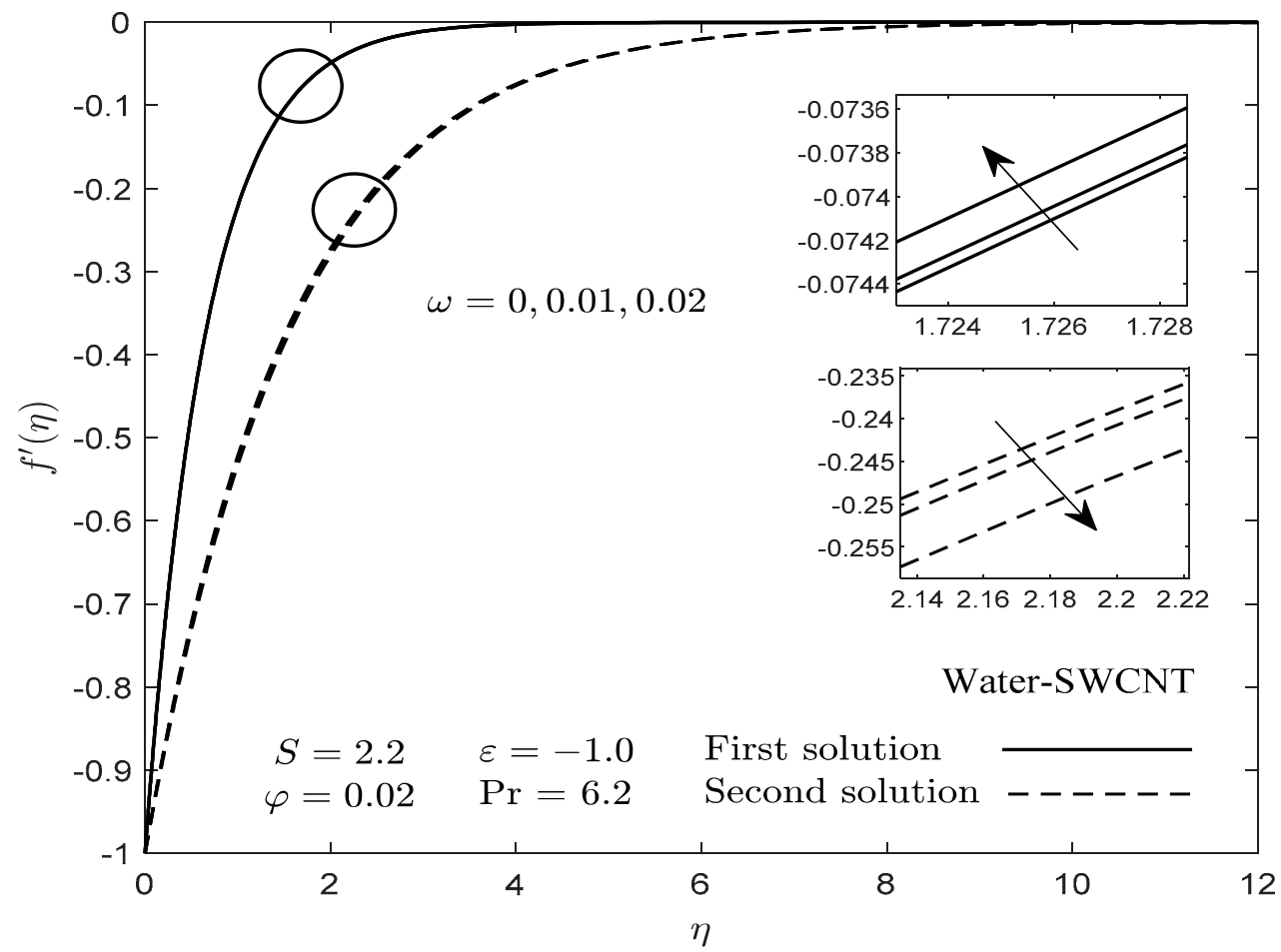

Figure 7. Velocity profiles of $x$-component $f^{\prime}(\eta)$ for some values of $\omega$.

The presence of more suspended particles in the flow decelerates the velocity of $x$ component because the surface is only compressed in the $x$-direction. Since the surface 
is not compressed in the $y$-direction, the velocity of $y$-component increases due to less collision between the suspended molecules. The higher nanoparticle rate that thickens the thermal boundary layer thickness, as in Figure 11, will prevent heat diffusion from the surface to the fluid. As a result, the temperature of the flow rises. As the suction parameter enhances, the velocity of $x$-component for the first solution rises, while the opposite phenomenon is observed for both the velocity of $y$-component and temperature profiles as presented in Figures 12-14, respectively. Moreover, all the profiles obtained in this work satisfy the endpoint boundary conditions (11) asymptotically, thus supporting the numerical results gained for the current study. Further, the boundary layer thickness near the surface for the first solution is thinner than the second solution.

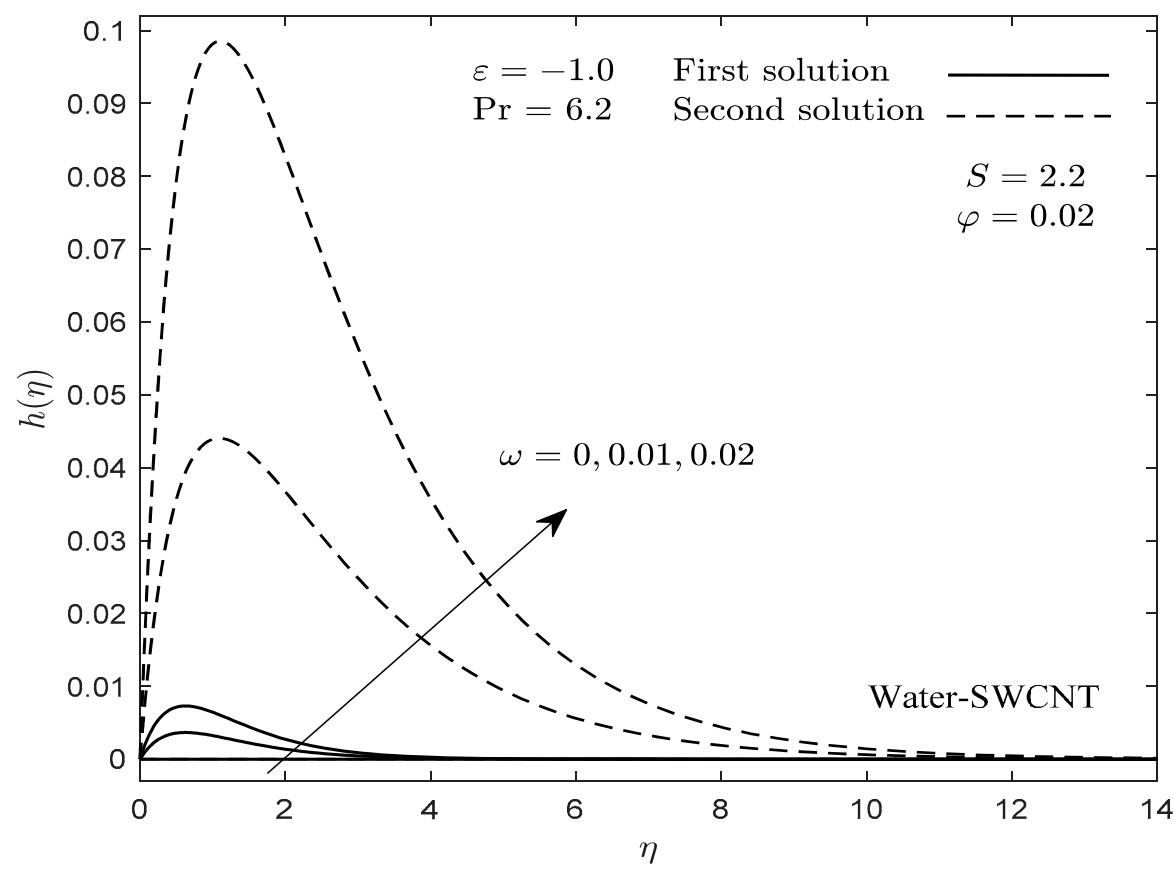

Figure 8. Velocity profiles of $y$-component $h(\eta)$ for some values of $\omega$.

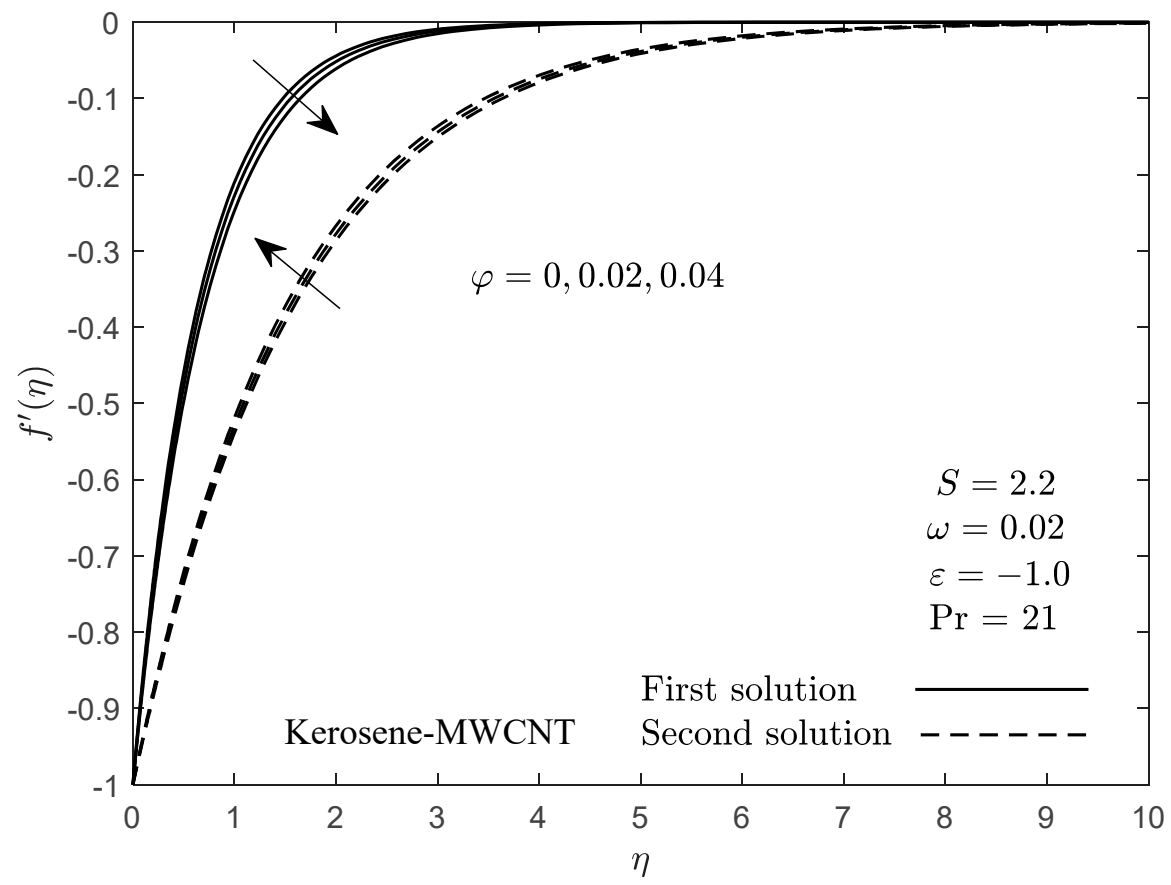

Figure 9. Velocity profiles of $x$-component $f^{\prime}(\eta)$ for some values of $\varphi$. 


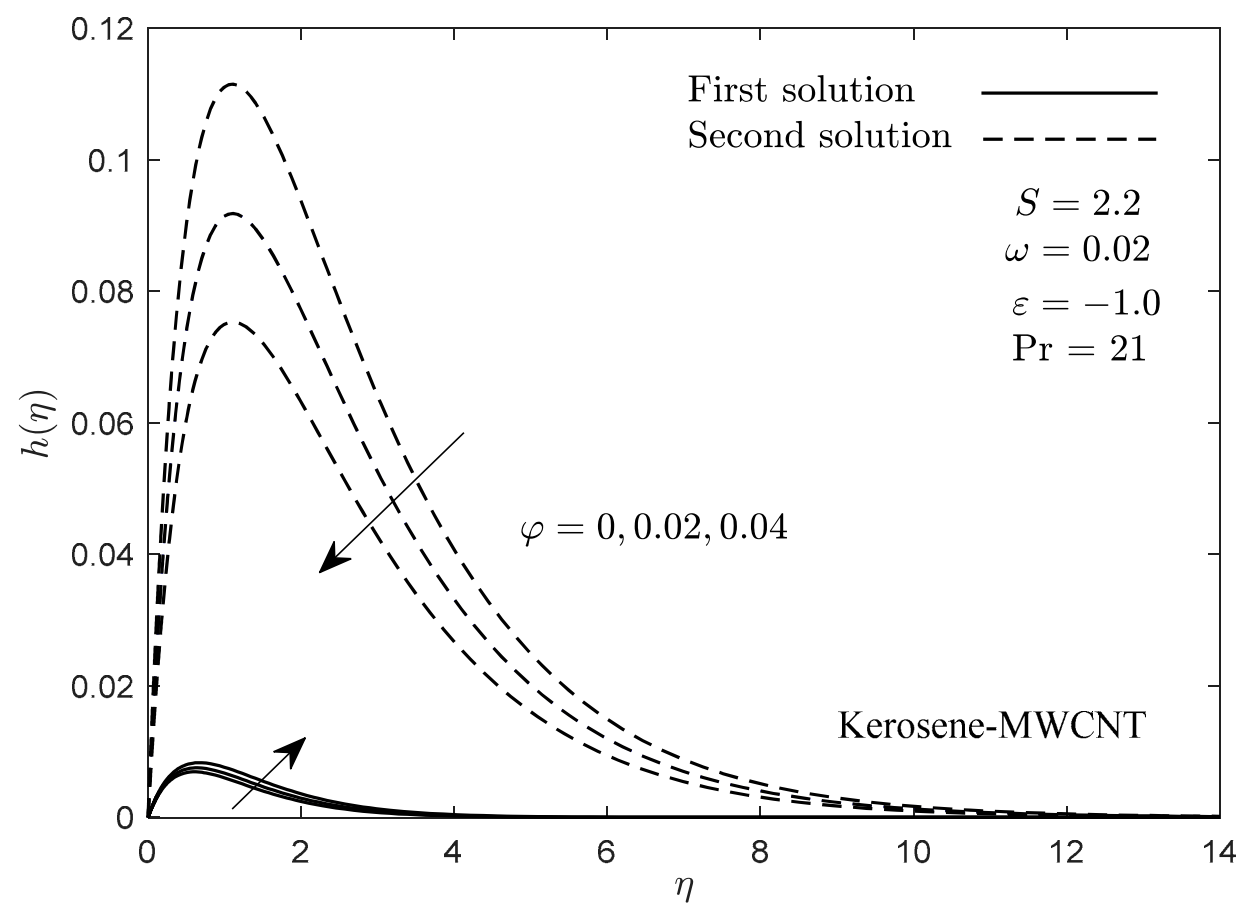

Figure 10. Velocity profiles of $y$-component $h(\eta)$ for some values of $\varphi$.

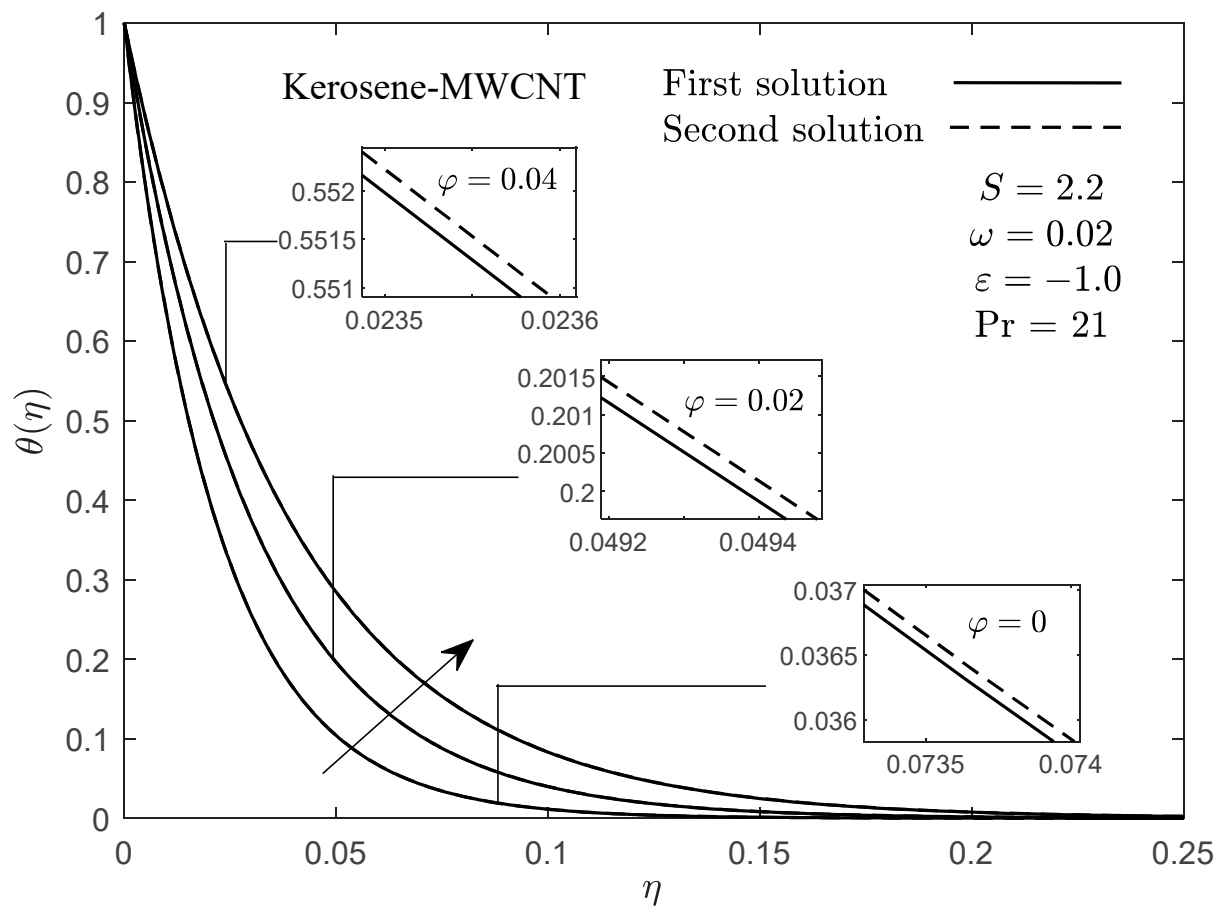

Figure 11. Temperature profiles $\theta(\eta)$ for some values of $\varphi$.

Tables 3 and 4 provide the numerical values of the skin friction coefficients of $x$ component $R e_{x}^{1 / 2} C_{f x}$ and $y$-component $R e_{x}^{1 / 2} C_{f y}$, for several values of $\varphi$, suction $S$, and $\omega$ for water and kerosene as the base fluids when $\varepsilon=1.0$ (stretching case), respectively. It is observed from Tables 3 and 4 , that an increase in $\varphi$ tends to decrease $\left|R e_{x}^{1 / 2} C_{f x}\right|$ and $\left|R e_{x}^{1 / 2} C_{f y}\right|$ for both water-SWCNT and kerosene-MWCNT as reported by Anuar et al. [18]. This result differs from prior findings for copper, titanium, and alumina nanoparticles (see Nadeem et al. [34]; Mabood et al. [54]; Dinarvand et al. [55]). Furthermore, as the parameter $S$ becomes more intense, the values of $\operatorname{Re}_{x}^{1 / 2} C_{f x}$ increase, while $R e_{x}^{1 / 2} C_{f y}$ decreases for both 
water-SWCNT and kerosene-MWCNT. This discovery demonstrates that the suction effect stimulates particle collisions which causes more friction in the $x$-direction. Moreover, the suction impact on the skin friction in $x$-component is more significant than $y$-component since the surface is stretched in the $x$-direction.

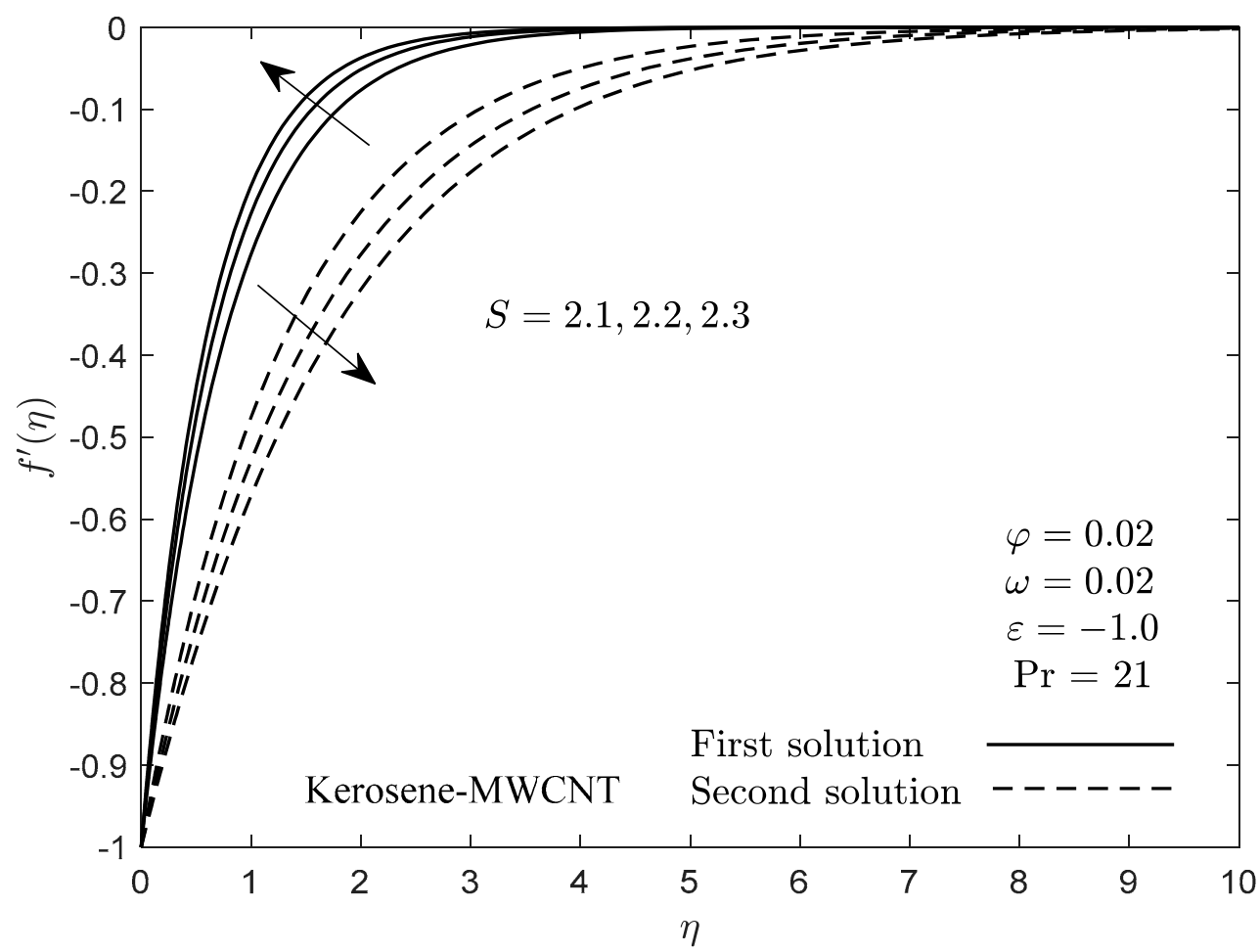

Figure 12. Velocity profiles of $x$-component $f^{\prime}(\eta)$ for some values of $S$.

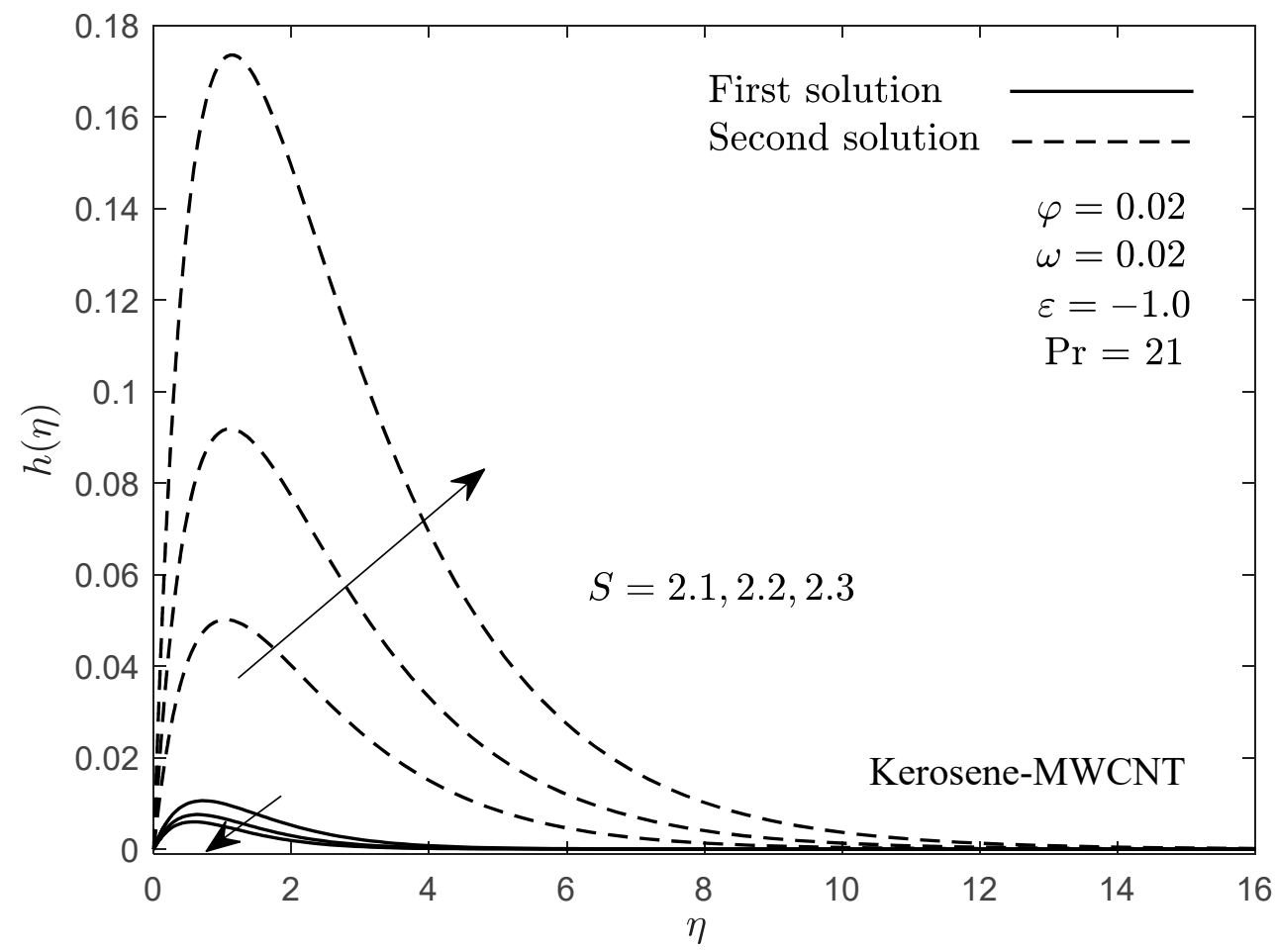

Figure 13. Velocity profiles of $y$-component $h(\eta)$ for some values of $S$. 
In addition, both values of $\left|R e_{x}^{1 / 2} C_{f x}\right|$ and $\left|R e_{x}^{1 / 2} C_{f y}\right|$ increased with a higher rotation rate. Physically, a high rotation rate causes the fluid to rotate continuously and generates more friction on the surface. The skin friction coefficients of the $x$-and $y$-components for SWCNTs are clearly higher than for MWCNTs. It is also worth noting that kerosene-based fluid has a greater $x$ - and $y$-components skin friction coefficient than those of water-based fluid. Moreover, a positive value of the skin friction coefficient indicates that the fluid exerts a drag force on the plate, whereas a negative sign suggests the opposite.

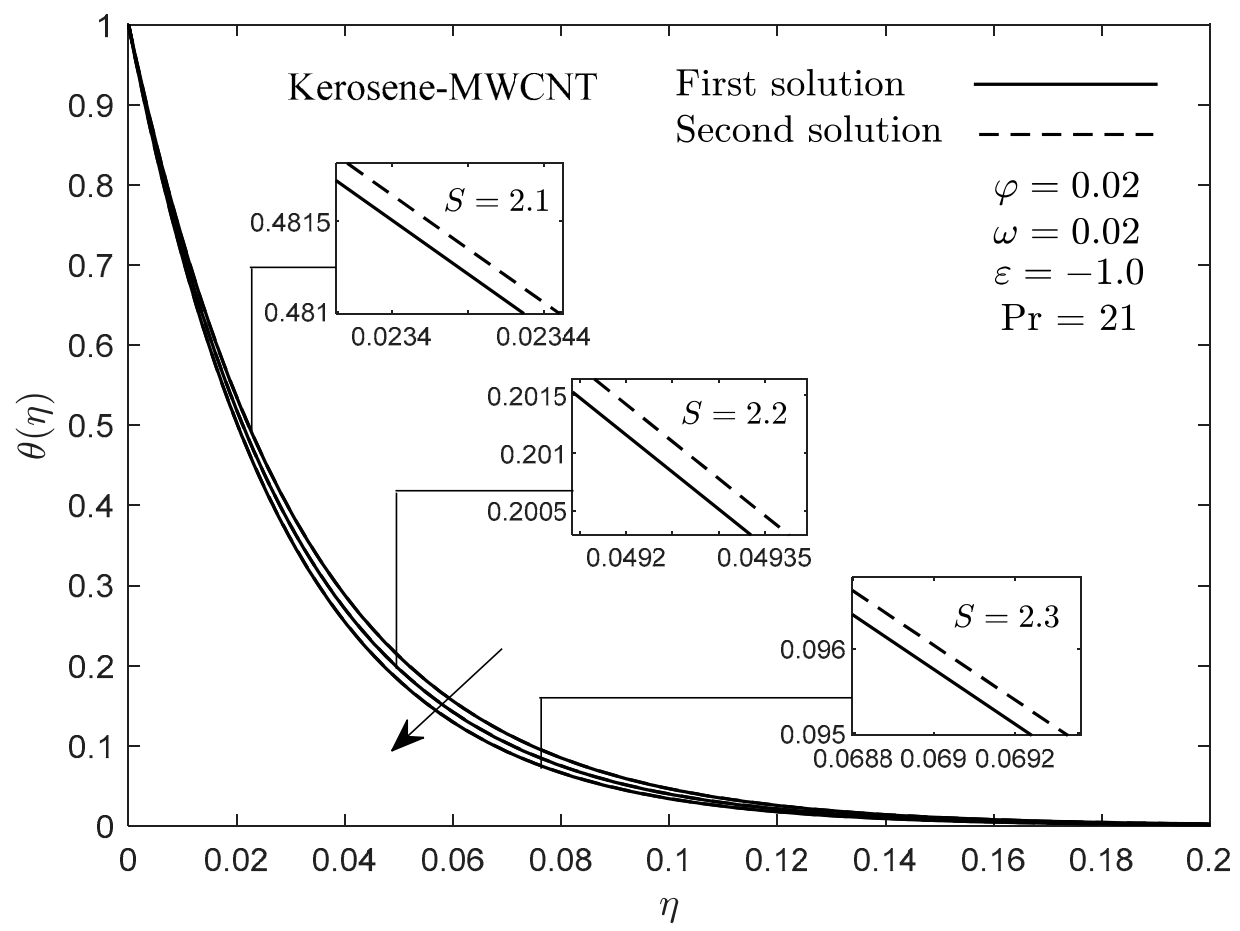

Figure 14. Temperature profiles $\theta(\eta)$ for some values of $S$.

Table 3. Values of $\operatorname{Re}_{x}^{1 / 2} C_{f x}$ for different values of $\varphi, S$, and $\omega$ when $\varepsilon=1.0$ (stretching case) for both water and kerosene base fluids.

\begin{tabular}{ccccccc}
\hline & & & Water & \multicolumn{3}{c}{ Kerosene } \\
\hline $\boldsymbol{c}$ & $\boldsymbol{S}$ & $\omega$ & SWCNT & MWCNT & SWCNT & MWCNT \\
\hline .01 & 0 & 0 & -1.02075 & -1.01570 & -1.02432 & -1.01791 \\
& 2.1 & 0.1 & -2.54543 & -2.52381 & -2.56079 & -2.53326 \\
& & 0.2 & -2.55136 & -2.52976 & -2.56670 & -2.53921 \\
& & 0.3 & -2.56096 & -2.53939 & -2.57628 & -2.54882 \\
& 2.2 & 0.1 & -2.63319 & -2.61061 & -2.64922 & -2.62049 \\
0.02 & & 0.2 & -2.63865 & -2.61610 & -2.65467 & -2.62596 \\
& & 0.3 & -2.64751 & -2.62499 & -2.66351 & -2.63484 \\
& 2.1 & 0.1 & -2.58922 & -2.54595 & -2.61994 & -2.56488 \\
& & 0.2 & -2.59532 & -2.55210 & -2.62602 & -2.57101 \\
& 2.2 & 0.3 & -2.60520 & -2.56204 & -2.63585 & -2.58092 \\
0.03 & 0.1 & -2.67828 & -2.63311 & -2.71036 & -2.65286 \\
& & 0.2 & -2.68390 & -2.63877 & -2.71595 & -2.65851 \\
& 2.1 & 0.3 & -2.69302 & -2.64796 & -2.72502 & -2.66767 \\
& & 0.1 & -2.63333 & -2.56839 & -2.67943 & -2.59680 \\
& & 0.2 & -2.63962 & -2.57475 & -2.68567 & -2.60312 \\
& 2.2 & 0.3 & -2.64979 & -2.58501 & -2.69577 & -2.61335 \\
& & 0.1 & -2.72368 & -2.65589 & -2.77181 & -2.68555 \\
& & 0.2 & -2.72948 & -2.66175 & -2.77756 & -2.69138 \\
& & -2.73887 & -2.67125 & -2.78688 & -2.70083 \\
\hline
\end{tabular}


Table 4. Values of $R e_{x}^{1 / 2} C_{f y}$ for different values of $\varphi, S$, and $\omega$ when $\varepsilon=1.0$ (stretching case) for both water and kerosene base fluids.

\begin{tabular}{ccccccc}
\hline & & & Water & \multicolumn{3}{c}{ Kerosene } \\
\hline $\boldsymbol{\varphi}$ & $\boldsymbol{S}$ & $\boldsymbol{\omega}$ & SWCNT & MWCNT & SWCNT & MWCNT \\
\hline 01 & 0 & 0 & -1.02075 & 0 & 0 & 0 \\
& 2.1 & 0.1 & -0.07556 & -0.07541 & -0.07566 & -0.07547 \\
& & 0.2 & -0.15042 & -0.15011 & -0.15063 & -0.15025 \\
& 2.2 & 0.3 & -0.22397 & -0.22349 & -0.22430 & -0.22370 \\
& & 0.1 & -0.07342 & -0.07328 & -0.07352 & -0.07334 \\
0.02 & 0.2 & -0.14624 & -0.14596 & -0.14644 & -0.14609 \\
& 2.1 & 0.3 & -0.21792 & -0.21749 & -0.21822 & -0.21768 \\
& & 0.1 & -0.07735 & -0.07705 & -0.07756 & -0.07718 \\
& & 0.2 & -0.15398 & -0.15336 & -0.15441 & -0.15363 \\
& 2.2 & 0.3 & -0.22925 & -0.22829 & -0.22992 & -0.22871 \\
0.03 & 0.1 & -0.07517 & -0.07489 & -0.07537 & -0.07502 \\
& & 0.2 & -0.14972 & -0.14915 & -0.15012 & -0.14940 \\
& 2.1 & 0.3 & -0.22309 & -0.22220 & -0.22370 & -0.22259 \\
& & 0.1 & -0.07920 & -0.07874 & -0.07952 & -0.07894 \\
& & 0.2 & -0.15765 & -0.15670 & -0.15830 & -0.15712 \\
& 2.2 & 0.3 & -0.23470 & -0.23322 & -0.23571 & -0.23387 \\
& & 0.1 & -0.07698 & -0.07655 & -0.07727 & -0.07674 \\
& & 0.2 & -0.15331 & -0.15244 & -0.15391 & -0.15282 \\
& & 0.3 & -0.22841 & -0.22706 & -0.22934 & -0.22766 \\
\hline
\end{tabular}

Table 5. Values of $\operatorname{Re}_{x}^{1 / 2} N u_{x}$ for different values of $\varphi, S$ and $\omega$ when $\varepsilon=1.0$ (stretching case) for both water and kerosene base fluids.

\begin{tabular}{ccccccc}
\hline & & & Water & & Kerosene \\
\hline $\boldsymbol{\varphi}$ & $\boldsymbol{S}$ & $\boldsymbol{\omega}$ & SWCNT & MWCNT & SWCNT & MWCNT \\
\hline 0.01 & 0 & 0 & 1.891986 & 1.882514 & 3.745629 & 3.726123 \\
& 2.1 & 0.1 & 13.36019 & 13.36137 & 44.48189 & 44.52129 \\
& & 0.2 & 13.35999 & 13.36118 & 44.48181 & 44.52122 \\
& & 0.3 & 13.35967 & 13.36086 & 44.48168 & 44.52109 \\
& 2.2 & 0.1 & 13.95826 & 13.95984 & 46.55247 & 46.59429 \\
0.02 & & 0.2 & 13.95809 & 13.95968 & 46.55240 & 46.59422 \\
& 2.1 & 0.3 & 13.95781 & 13.95941 & 46.55230 & 46.59412 \\
& & 0.1 & 13.31519 & 13.31824 & 44.42055 & 44.49977 \\
& & 0.2 & 13.31494 & 13.31799 & 44.42045 & 44.49967 \\
& 2.2 & 0.3 & 13.31453 & 13.31759 & 44.42027 & 44.49950 \\
& & 0.1 & 13.90693 & 13.91074 & 46.48099 & 46.56501 \\
& & 0.2 & 13.90671 & 13.91053 & 46.48090 & 46.56492 \\
& 2.1 & 0.3 & 13.90636 & 13.91019 & 46.48076 & 46.56478 \\
& & 0.1 & 13.26841 & 13.27395 & 44.35873 & 44.47819 \\
& & 0.2 & 13.26810 & 13.27364 & 44.35859 & 44.47806 \\
& 2.2 & 0.3 & 13.26758 & 13.27315 & 44.35837 & 44.47784 \\
& & 0.1 & 13.85391 & 13.86056 & 46.40909 & 46.53571 \\
& & 0.2 & 13.85364 & 13.86030 & 46.40898 & 46.53560 \\
& & 0.3 & 13.85320 & 13.85988 & 46.40879 & 46.53542 \\
\hline
\end{tabular}

The numerical values of the local Nusselt number $R e_{x}^{-1 / 2} N u_{x}$ for some values of nanoparticle volume fraction $\varphi$, suction $S$ and rotation parameter $\omega$ are given in Table 5 when $\varepsilon=1.0$ (stretching case). It is seen in Table 5 that the values of $R e_{x}^{-1 / 2} N u_{x}$ increase with increasing $\varphi$ for both water/kerosene-SWCNTs and water/kerosene-MWCNTs. However, the opposite observation was found for $-\theta^{\prime}(0)$, as displayed in Figure 6. It demonstrates that the thermal conductivity formula affects the heat transfer rate at the surface since it involves nanoparticle volume fraction (see Equations (6) and (15)). As a result of this circumstance, numerous studies are attempting to acquire the most effective 
thermal conductivity, as noted by Li et al. [56] and Fabre and Murshed [57]. However, a similar pattern was obtained for the values of $R e_{x}^{-1 / 2} N u_{x}$ and $-\theta^{\prime}(0)$, where a higher suction rate leading to an increase in $R e_{x}^{-1 / 2} N u_{x}$ and $-\theta^{\prime}(0)$. In contrast, the values of $R e_{x}^{-1 / 2} N u_{x}$ and $-\theta^{\prime}(0)$ decreased with the presence of the rotating fluid in the flow. This is due to the fluid rotation delaying heat transmission from the surface to the surrounding fluid, and the opposite trend occurs as suction increases.

Table 6. Minimum eigenvalues $\gamma$ for multiple values of $\omega$ and $\varepsilon$ when $\varphi=0.02, S=2.2$, and $\operatorname{Pr}=6.2$ (water) for SWCNT.

\begin{tabular}{cccc}
\hline $\boldsymbol{\omega}$ & $\boldsymbol{\varepsilon}$ & First Solutions & Second Solutions \\
\hline 0.0 & -1.1826 & 0.0891 & -0.0861 \\
& -1.1820 & 0.0946 & -0.0912 \\
0.01 & -1.1800 & 0.1110 & -0.1063 \\
& -1.1849 & 0.0732 & -0.0712 \\
0.02 & -1.1840 & 0.0829 & -0.0803 \\
& -1.1800 & 0.1168 & -0.1117 \\
& -1.1899 & 0.0268 & -0.0265 \\
& -1.1890 & 0.0473 & -0.0464 \\
\hline
\end{tabular}

In the absence of suction and rotation parameters when $\varphi=0.01$, SWCNT produces higher heat transfer rate than MWCNT for both water and kerosene base fluids. Without any disturbances like rotation in the fluid and suction at the surface, heat is quickly diffused through the thin wall (SWCNT) compared to the thick wall (MWCNT). In contrast, when there are suction and rotation parameters, a higher heat transfer rate is obtained for MWCNT. It is also found that kerosene has a higher heat transfer rate than water since it has a greater Prandtl number $(\operatorname{Pr}=21)$ than water $(\operatorname{Pr}=6.2)$.

Basically, the solution is stable if the trajectories do not deviate significantly in response to a slight perturbation and have the same values of $f^{\prime \prime}(0), h^{\prime}(0)$, and $-\theta^{\prime}(0)$ for $\eta_{\infty}$. In this study, the second solution is not stable since the solution is only valid for certain values of boundary layer thicknesses compared to the first solution. However, the existence of second solutions cannot be ignored since they may have physical sense in some circumstances. In this study, the stability analysis proposed by Merkin [37] was performed to determine which solution was stable as time evolved, by solving Equations (30)-(33) using bvp4c solver in MATLAB software. The values of the smallest eigenvalue $\gamma$ for some values of rotation and stretching or shrinking parameters are generated and tabulated in Table 6 for single-wall carbon nanotubes. It was found that the values of the smallest eigenvalues $\gamma$ for the first solutions were positive, whereas the second solutions had negative values. Referring to Equation (25), the flow was unstable since the initial growth of disturbance occurred for the negative value of $\gamma$. In contrast, the flow was stable when $\gamma$ took the positive value, which implies an initial decay of disturbance in the system. It was noticed that as $\varepsilon$ approached its critical value $\varepsilon_{c}$, the smallest eigenvalue tended to zero for both first and second solutions, as shown in Figure 15. This criterion indicates that the transition occurs at the turning point. Figure 15 also shows the region for the stable and unstable solutions. 


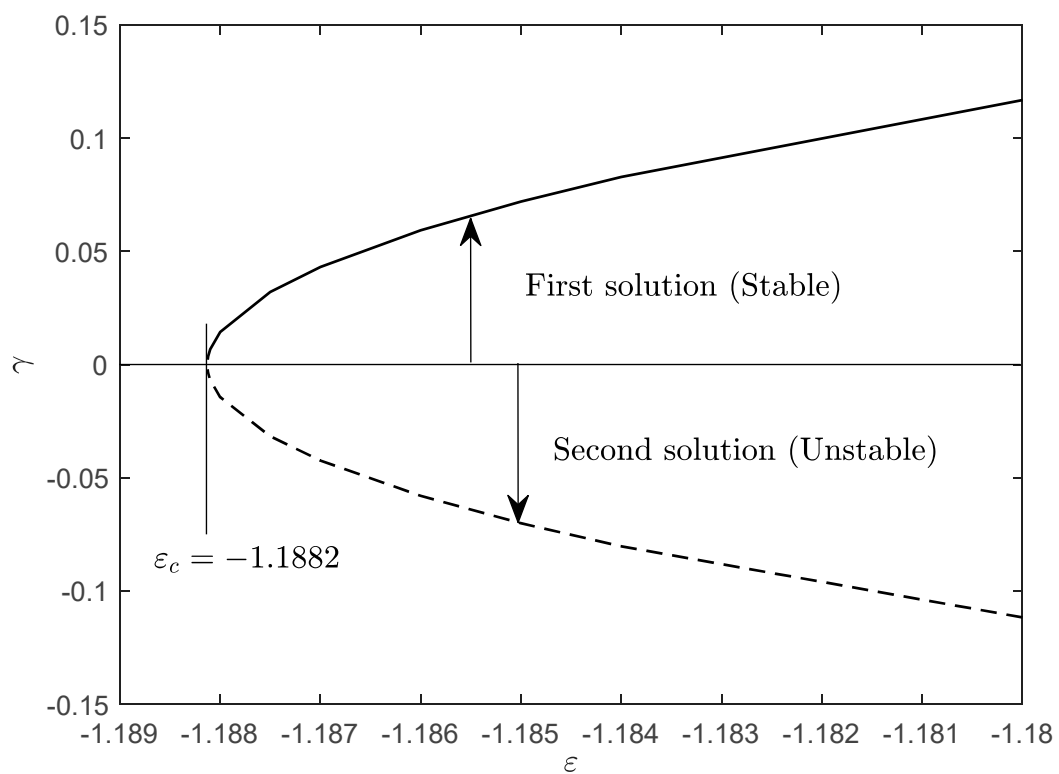

Figure 15. Minimum eigenvalues $\gamma$ versus $\varepsilon$ when $\omega=0.01, \varphi=0.02, S=2.2$, and $\operatorname{Pr}=6.2$ (water) for SWCNT.

\section{Conclusions}

In the present paper, the numerical results of a steady rotational flow past a stretching/shrinking surface in a nanofluid with carbon nanotube as the nanoparticles (SWCNTs and MWCNTs) were obtained using bvp4c solver in MATLAB and reported in Tables and graphs. One of the most important discoveries in this paper is that dual solutions exist for the shrinking surface, and we found that only the first solution is stable in the long run. Moreover, the heat transfer enhancement is higher in water-MWCNTs than in water-SWCNTs. Kerosene-based carbon nanotubes have a higher heat transfer rate than water-based carbon nanotubes. Other findings of this study can be summarized as follows:

- Increasing nanoparticle volume fraction tends to increase the heat transfer at the surface, while decreasing the temperature gradient in both nanofluids;

- The heat transfer rate at the surface is increased by suction parameter, whereas it decreases by rotating flow parameter in both nanofluids;

- In both nanofluids, increasing the nanoparticle volume fraction reduces the friction on the surface in the $x$ and $y$ directions, whereas rotational flow increases it;

- $\quad$ The friction in $x$ direction is higher than in $y$ direction in both nanofluids.

Author Contributions: Writing-original draft, N.A.Y.; formulation and methodology, N.F.D., N.A.Y. and S.N.A.S.; generating numerical results: S.N.A.S. and N.A.Y.; validation, N.A.Y.; writing-review and editing, A.I. and I.P.; supervising, A.I.; funding acquisition, A.I. All authors have read and agreed to the published version of the manuscript.

Funding: This research was funded by the Universiti Kebangsaan Malaysia (DIP-2020-001).

Institutional Review Board Statement: Not applicable.

Informed Consent Statement: Not applicable.

Data Availability Statement: Not applicable.

Acknowledgments: The first author would like to thank Universiti Teknologi MARA for supporting her sabbatical leave.

Conflicts of Interest: The authors declare no conflict of interest. 


\section{References}

1. Choi, S.U.S.; Eastman, J.A. Enhancing Thermal Conductivity of Fluids with Nanoparticles. In Proceeding of the ASME International Mechanical Engineering Congress and Exposition, San Francisco, CA, USA, 12-17 November 1995; Volume 66, pp. 99-105.

2. Das, S.K.S.; Choi, U.S.; Yu, W.; Pradeep, T. Nanofluids: Science and Technology; John Wiley \& Sons: Hoboken, NJ, USA, 2008; pp. 1-10.

3. Waqas, H.; Farooq, U.; Alghamdi, M.; Muhammad, T. Significance of surface-catalyzed reactions in $\mathrm{SiO}_{2}-\mathrm{H}_{2} \mathrm{O}$ nanofluid flow through porous media. Case Stud. Therm. Eng. 2021, 27, 101228. [CrossRef]

4. Subhashini, S.V.; Sumathi, R. Dual solutions of a mixed convection flow of nanofluids over a moving vertical plate. Int. J. Heat Mass Transf. 2014, 71, 117-124. [CrossRef]

5. Bachok, N.; Ishak, A.; Pop, I. Flow and heat transfer characteristics on a moving plate in a nanofluid. Int. J. Heat Mass Transf. 2012, 55, 642-648. [CrossRef]

6. Ahmadi, M.H.; Mirlohi, A.; Nazari, M.A.; Ghasempour, R. A review of thermal conductivity of various nanofluids. J. Mol. Liq. 2018, 265, 181-188. [CrossRef]

7. Othman, N.A.; Yacob, N.A.; Bachok, N.; Ishak, A.; Pop, I. Mixed convection boundary-layer stagnation point flow past a vertical stretching/shrinking surface in a nanofluid. Appl. Therm. Eng. 2017, 115, 1412-1417. [CrossRef]

8. Jamaludin, A.; Nazar, R.; Pop, I. Mixed convection stagnation point flow of a nanofluid past a permeable stretching/shrinking sheet in the presence of thermal radiation and heat source/sink. Energies 2019, 12, 788. [CrossRef]

9. Komeilibirjandi, A.; Raffiee, A.H.; Maleki, A.; Nazari, M.A.; Shadloo, M.S. Thermal conductivity prediction of nanofluids containing $\mathrm{CuO}$ nanoparticles by using correlation and artificial neural network. J. Therm. Anal. Calorim. 2019, 139, $2679-2689$. [CrossRef]

10. Popov, V.N. Carbon nanotubes: Properties and application. Mater. Sci. Eng. R Rep. 2004, 43, 61-102. [CrossRef]

11. Patel, P.R.; Sharma, S.; Tiwari, S.K. Governing parameters for pull-out of carbon nanotubes from aluminium composites: A review. Mater. Today Proc. 2021, 44, 4827-4832. [CrossRef]

12. Taherian, H.; Alvarado, J.L.; Languri, E.M. Enhanced thermophysical properties of multi-walled carbon nanotubes based nanofluids. Part 1: Critical review. Renew. Sustain. Energy Rev. 2018, 82, 4326-4336. [CrossRef]

13. Khan, W.A.; Khan, Z.H.; Rahi, M. Fluid flow and heat transfer of carbon nanotubes along a flat plate with Navier slip boundary. Appl. Nanosci. 2014, 4, 633-641.

14. Akbar, N.S.; Khan, Z.H.; Nadeem, S. The combined effects of slip and convective boundary conditions on stagnation-point flow of CNT suspended nanofluid over a stretching sheet. J. Mol. Liq. 2014, 196, 21-25. [CrossRef]

15. Hayat, T.; Hussain, Z.; Alsaedi, A.; Asghar, S. Carbon nanotubes effects in the stagnation point flow towards a nonlinear stretching sheet with variable thickness. Adv. Powder Technol. 2016, 27, 1677-1688. [CrossRef]

16. Hussain, Z.; Hayat, T.; Alsaedi, A.; Ahmad, B. Three-dimensional convective flow of CNTs nanofluids with heat generation/absorption effect: A numerical study. Comput. Methods Appl. Mech. Eng. 2018, 329, 40-54. [CrossRef]

17. Sreedevi, P.; Reddy, P.S.; Chamkha, A.J. Magneto-hydrodynamics heat and mass transfer analysis of single and multi-wall carbon nanotubes over vertical cone with convective boundary condition. Int. J. Mech. Sci. 2018, 135, 646-655. [CrossRef]

18. Anuar, N.S.; Bachok, N.; Arifin, N.M.; Rosali, H. Role of multiple solutions in flow of nanofluids with carbon nanotubes over a vertical permeable moving plate. Alex. Eng. J. 2020, 59, 763-773. [CrossRef]

19. Reddy, P.S.; Sreedevi, P. Effect of thermal radiation and volume fraction on carbon nanotubes based nanofluid flow inside a square chamber. Alex. Eng. J. 2020, 60, 1807-1817. [CrossRef]

20. Ramzan, M.; Shah, S.R.Z.; Kumam, P.; Thounthong, P. Unsteady MHD carbon nanotubes suspended nanofluid flow with thermal stratification and nonlinear thermal radiation. Alex. Eng. J. 2020, 59, 1557-1566. [CrossRef]

21. Ul Haq, R.; Soomro, F.A.; Öztop, H.F.; Mekkaoui, T. Thermal management of water-based carbon nanotubes enclosed in a partially heated triangular cavity with heated cylindrical obstacle. Int. J. Heat Mass Transf. 2019, 131, 724-736. [CrossRef]

22. Reddy, P.S.; Jyothi, K.; Reddy, M.S. Flow and heat transfer analysis of carbon nanotubes based Maxwell nanofluid flow driven by rotating stretchable disks with thermal radiation. J. Braz. Soc. Mech. Sci. Eng. 2018, 40, 576. [CrossRef]

23. Li, X.; Chen, W.; Zou, C. The stability, viscosity and thermal conductivity of carbon nanotubes nanofluids with high particle concentration: A surface modification approach. Powder Technol. 2020, 361, 957-967. [CrossRef]

24. Peter, R.N.C. Rotating Flow; Elsevier: Woburn, UK, 2011; pp. 1-2.

25. Singh, M.P.; Sathi, H.L. An Exact Solution in Rotating Flow. J. Math. Mech. 1968, 18, 193-200. [CrossRef]

26. Wang, C.Y. Stretching a surface in a rotating fluid. Z. Angew. Math. Phys. ZAMP 1988, 39, 177-185. [CrossRef]

27. Nazar, R.; Amin, N.; Pop, I. Unsteady boundary layer flow due to a stretching surface in a rotating fluid. Mech. Res. Comm. 2004, 31, 121-128. [CrossRef]

28. Ali, F.M.; Nazar, R.; Arifin, N.M.; Pop, I. Unsteady shrinking sheet with mass transfer in a rotating fluid. Int. J. Numer. Meth. Fluids 2011, 66, 1465-1474. [CrossRef]

29. Sreelakshmi, K.; Nagendramma, V.; Sarojamma. Unsteady boundary layer flow induced by a stretching sheet in a rotating fluid with thermal radiation. Procedia Eng. 2015, 127, 678-685.

30. Rosali, H.; Ishak, A.; Nazar, R.; Pop, I. Rotating flow over an exponentially shrinking sheet with suction. J. Mol. Liq. 2015, 211, 965-969. [CrossRef] 
31. Rana, P.; Bhargava, R.; Bég, O.A. Finite element simulation of unsteady magneto-hydrodynamic transport phenomena on a stretching sheet in a rotating nanofluid. Proc. Inst. Mech. Eng. Part N J. Nanoeng. Nanosyst. 2013, 227, 77-99. [CrossRef]

32. Bakar, N.A.A.; Bachok, N.; Arifin, N.M. Rotating flow over a shrinking sheet in nanofluid using Buongiorno model and thermophysical properties of nanoliquids. J. Nanofluids 2017, 6, 1215-1226. [CrossRef]

33. Krishna, M.V. Hall and ion slip effects on radiative MHD rotating flow of Jeffreys fluid past an infinite vertical flat porous surface with ramped wall velocity and temperature. Int. Commun. Heat Mass Transf. 2021, 126, 105399. [CrossRef]

34. Nadeem, S.; Rehman, A.U.; Mehmood, R. Boundary Layer Flow of Rotating Two Phase Nanofluid Over a Stretching Surface. Heat Transf. Asian Res. 2016, 45, 285-298. [CrossRef]

35. Dzulkifli, N.F.; Bachok, N.; Yacob, N.A.; Arifin, N.M.; Rosali, H. Unsteady boundary layer rotating flow and heat transfer in a copper-water nanofluid over a stretching sheet. Malays. J. Math. Sci. 2017, 11, 21-33.

36. Salleh, S.N.A.; Bachok, N.; Arifin, N.M. Stability analysis of a rotating flow toward a shrinking permeable surface in nanofluid Malays. J. Math. Sci. 2019, 38, 19-32. [CrossRef]

37. Merkin, J.H. On dual solutions occurring in mixed convection in a porous medium. J. Eng. Math. 1986, 20, 171-179. [CrossRef]

38. Harris, S.D.; Ingham, D.B.; Pop, I. Mixed convection boundary-layer flow near the stagnation point on a vertical surface in a porous medium: Brinkman model with slip. Transp. Porous Med. 2009, 77, 267-285. [CrossRef]

39. Mustafa, I.; Abbas, Z.; Arif, A.; Javed, T.; Ghaffari, A. Stability analysis for multiple solutions of boundary layer flow towards a shrinking sheet: Analytical solution by using least square method. Phys. A Stat. Mech. Appl. 2020, 540, 123028. [CrossRef]

40. Tshivhi, K.S.; Makinde, O.D. Magneto-nanofluid coolants past heated shrinking/stretching surfaces: Dual solutions and stability analysis. Results Eng. 2021, 10, 100229. [CrossRef]

41. Hafeez, M.U.; Hayat, T.; Alsaedi, A.; Khan, M.I. Numerical simulation for electrical conducting rotating flow of Au (Gold)-Zn (Zinc)/EG (Ethylene glycol) hybrid nanofluid. Int. Commun. Heat Mass Transf. 2021, 124, 105234. [CrossRef]

42. Mehdipour, M.; Keshavarz, P.; Rahimpour, M.R. Rotating liquid sheet contactor: A new gas-liquid contactor system in CO, absorption by nanofluids. Chem. Eng. Process. Process Intensif. 2021, 165, 108447. [CrossRef]

43. Acharya, N.; Das, K.; Kundu, P.K. Rotating flow of carbon nanotube over a stretching surface in the presence of magnetic field: A comparative study. Appl. Nanosci. 2018, 8, 369-378. [CrossRef]

44. Shah, Z.; Bonyah, E.; Islam, S.; Gul, T. Impact of thermal radiation on electrical MHD rotating flow of carbon nanotubes over a stretching sheet. AIP Adv. 2019, 9, 015115. [CrossRef]

45. Noranuar, W.N.N.; Mohamad, A.Q.; Shafie, S.; Khan, I.; Jiann, L.Y.; Ilias, M.R. Non-coaxial rotation flow of MHD Casson nanofluid carbon nanotubes past a moving disk with porosity effect. Ain Shams Eng. J. 2021, 12, 4099-4110. [CrossRef]

46. Hussain, A.; Arshad, M.; Hassan, A.; Rehman, A.; Ahmad, H.; Baili, J.; Gia, T.N. Heat transport investigation of engine oil based rotating nanomaterial liquid flow in the existence of partial slip effect. Case Stud. Therm. Eng. 2021, 28, 101500. [CrossRef]

47. Manjunatha, P.T.; Punith Gowda, R.J.; Kumar, R.N.; Suresha, S.; Sarwe, D.U. Numerical simulation of carbon nanotubes nanofluid flow over vertically moving disk with rotation. Partial Differ. Equ. Appl. Math. 2021, 4, 100124. [CrossRef]

48. Anusha, T.; Mahabaleshwar, U.S.; Sheikhnejad, Y. An MHD of Nanofluid Flow Over a Porous Stretching/Shrinking Plate with Mass Transpiration and Brinkman Ratio. Transp. Porous Med. 2021, in press. [CrossRef]

49. Xue, Q.Z. Model for thermal conductivity of carbon nanotube-based composites. Phys. Rev. B Condens. Matter. 2005, 368, 302-307. [CrossRef]

50. Babar, H.; Ali, H.M. Towards hybrid nanofluids: Preparation, thermophysical properties, applications, and challenges. J. Mol. Liq. 2019, 281, 598-633. [CrossRef]

51. Weidman, P.D.; Kubitschek, D.G.; Davis, A.M.J. The effect of transpiration on self-similar boundary layer flow over moving surfaces. Int. J. Eng. Sci. 2006, 44, 730-737. [CrossRef]

52. Shampine, L.F.; Gladwell, I.; Thompson, S. Solving ODEs with Matlab; Cambridge University Press: New York, NY, USA, 2006; pp. 133-168.

53. Mustafa, M.; Mushtaq, A.; Hayat, T.; Alsaedi, A. Rotating flow of magnetite-water nanofluid over a stretching surface inspired by nonlinear thermal radiation. PLoS ONE 2016, 11, e0149304. [CrossRef]

54. Mabood, F.; Ibrahim, S.M.; Kumar, P.V.; Khan, W.A. Viscous dissipation effects on unsteady mixed convective stagnation point flow using Tiwari-Das nanofluid model. Results Phys. 2017, 7, 280-287. [CrossRef]

55. Dinarvand, S.; Hosseini, R.; Pop, I. Axisymmetric mixed convective stagnation-point flow of a nanofluid over a vertical permeable cylinder by Tiwari-Das nanofluid model. Powder Technol. 2017, 311, 147-156. [CrossRef]

56. Li, J.; Zhang, X.; Xu, B.; Yuan, M. Nanofluid research and applications: A review. Int. Commun. Heat Mass Transf. 2021, 127, 105543. [CrossRef]

57. Fabre, E.; Murshed, S.M.S. A comprehensive review of thermophysical properties and prospects of ionanocolloids in thermal energy applications. Renew. Sustain. Energy Rev. 2021, 151, 111593. [CrossRef] 